\title{
CONFLICTOS SOCIOECONÓMICOS Y AMBIENTALES DERIVADOS DE LA DISTRIBUCIÓN ECOLÓGICA EN LA Cuenca Carbonífera de la Sinifaná en Colombia
}

\author{
Liliana Lotero Álvarez ${ }^{\mathrm{a}}$
}

Fecha de recepción: 22 de junio de 2018. Fecha de aceptación: 15 de enero de 2019.

https://doi.org/10.22201/iiec.20078951e.2019.198.65857

Resumen. El artículo consiste en la distribución ecológica, la cual es analizada a partir de los conflictos socioeconómico y ambientales generados por la explotación del carbón en la Cuenca Carbonífera de la Sinifaná (cCs) en Antioquia-Colombia. La metodología se realizó bajo un enfoque descriptivo donde se caracterizaron los conflictos socioeconómico y ambientales y analítico con énfasis relacional, donde se contrastó la hipótesis de relación entre los conflictos socioeconómico y ambientales, la distribución ecológica y los Objetivos de Desarrollo Sostenible. Se concluye que el mayor conflicto que se presenta en la zona de estudio está asociado con la insostenibilidad ambiental, derivada de la práctica de la minería ilegal o informal, ocasionando un sinnúmero de conflictos socioeconómico y ambientales que están impactando en el bienestar de las personas que habitan en la ccs.

Palabras clave: desarrollo sostenible; distribución ecológica; conflictos ecológicodistributivos; explotación de carbón; minería; recursos naturales.

Clasificación JEL: L71, L72, O13, P28, Q01.

\section{SOCIOECONOMIC AND ENVIRONMENTAL CONFLICTS CAUSED BY ecological distribution in the Sinifaná Coalfield, Colombia}

\begin{abstract}
This paper analyzes ecological distribution, with a focus on the socioeconomic and environmental conflicts generated by coal exploitation in the Sinifaná coalfield (SCF), in Antioquia, Colombia. The methodology incorporated a descriptive approach which focused on socioeconomic and environmental conflicts, and an analytical approach with a relational emphasis. The hypothesized relation between socioeconomic and environmental conflicts and the Sustainable Development Goals was corroborated. In conclusion, the main conflict present in the study area surrounds the environmental sustainability that derives from informal and illegal mining practices. This causes countless socioeconomic and environmental conflicts that are impacting the wellbeing of people living in the SCF.
\end{abstract}

Key Words: sustainable development; ecological distribution; ecological-distributive conflicts; coal exploitation, mining; natural resources.

\footnotetext{
${ }^{a}$ Universidad Pontificia Bolivariana, Colombia. Correo electrónico: liliana.lotero@upb.edu.co
} 


\section{INTRODUCCIÓN}

La explotación del carbón en Colombia, en los últimos años, se ha intensificado debido al incremento en los precios de los recursos naturales, al aumento de la demanda energética por parte de los países desarrollados, así como por las políticas estatales establecidas para atraer inversionistas extranjeros a los países productores (Portafolio, 2012, p. 1), además de la generación de nuevos proyectos mineros de exploración y explotación.

La participación de Antioquia en la producción total de carbón en Colombia, representa $0.11 \%$ (5.105 toneladas) y se concentra en la Cuenca Carbonífera de la Sinifaná (cCs) con una producción de 2485 toneladas (Municipio de Amagá datos parciales de 2018) [Sistema de Información Minero Colombiano y Agencia Nacional de Minería (simco), 2018, p. 22], abarca una extensión territorial de $236 \mathrm{~km}^{2}$, compuesta por los municipios de Amagá, Angelópolis, Fredonia, Titiribí y Venecia (Gobernación de Antioquia, 2007, p. 9).

En la CCs, el tipo de minería que se trabaja es la de socavón o subterránea, lo que originó desde los años noventa del siglo pasado, un sinnúmero de conflictos no sólo ambientales, sino de carácter social y económico en las poblaciones donde se realizan las explotaciones mineras. Como lo afirma Bebbington (2009, p. 24): "La expansión espacial de la minería no ocurre en tierras vacías. Por el contrario, se da en tierras ya ocupadas y que son propiedad de otros, tierras que tienen significados culturales e históricos para sus moradores y tierras que son la fuente de diversos activos naturales que sustentan las estrategias de vida de estos pobladores".

La postura a tales conflictos ha sido diversa: "desde el Estado y las empresas mineras ha variado desde el silenciamiento y la negación, pasando por los mecanismos de autorregulación que han estado acompañados del discurso de responsabilidad social empresarial" (De Echave et al., 2009, p. 18).

Dichas consideraciones fundamentan el tema central de este artículo: la distribución ecológica entendida como: "los patrones sociales, espaciales y temporales de acceso a los beneficios obtenibles de los recursos naturales y a los servicios proporcionados por el ambiente como un sistema de soporte de vida" (Martínez-Alier, 2004b, p. 104), analizada a partir de los conflictos ecológico-distributivos (CED) generados por la explotación del carbón y surgidos por el acceso a los recursos naturales y servicios ambientales, los niveles de contaminación y la incidencia de riesgos ecológicos (Martínez-Alier, 2004b, p. 134).

Asociado al aumento de los CED y para dar respuesta a esta situación, fue necesario rastrear los CED existentes en el país desde la década de los noventa 
(modificación de la Constitución Política de Colombia), con el objetivo de verificar el Desarrollo Sostenible (DS) en la CCs. Este planteamiento se realizó bajo la concepción teórica de la Ecología Política, misma que se define como: "el estudio de los conflictos sociales sobre el acceso a los recursos y servicios ambientales y su destrucción” (Martínez-Alier, 2004b, p. 106) y el Ds como lo define el Informe Brundtland: "satisfacer las necesidades de la generación presente sin comprometer la capacidad de las generaciones futuras para satisfacer sus propias necesidades" (1987, p. 24) y Sachs (2016, p. 29): "el desarrollo sostenible es una forma de entender el mundo como interacción compleja entre sistemas económicos, sociales, ambientales y políticos", y que desde una mirada normativa lo articula a los Objetivos de Desarrollo Sostenible (oDs) que son el punto de partida a nivel mundial para el análisis de la sostenibilidad.

Para tal efecto, en este artículo se plantean variables de análisis que pretenden dar sentido al estudio del carbón como servicio ecosistémico no renovable y son los siguientes: Desarrollo Sostenible, Objetivos de Desarrollo Sostenible, Distribución Ecológica y conflictos ecológico-distributivos (leáse conflictos socioeconómicos y ambientales).

Desde el concepto de DS se consultó a varios teóricos que lo han interpretado de varias maneras, por ejemplo, Riechmann y Naredo (1995), Pierri (2005), Adams (1990), Serrano (1997) y Canut (2007), quienes expresan que es un concepto confuso, debido a que separa medio ambiente y desarrollo y que por ende se basa sólo en objetivos económicos y sociales dejando a un lado lo ambiental. Dentro del soporte teórico central está la Ecología Política, disciplina en construcción, que realiza aportes a diferentes disciplinas que convergen en ella, conviene decir que "la Ecología Política es un conjunto de intereses comunes que se trabajan desde perspectivas que provienen de las ciencias naturales como de las sociales, lo que le confiere su carácter interdisciplinario" (Durand et al., 2011, p. 8; Palacio, 2006).

La Ecología Política abre el espacio al estudio de los CED como una propuesta de Martínez-Alier (2004a, p. 134), que surgen de una distribución ecológica desigual y son disputas sobre los niveles de contaminación, la incidencia de riesgos ecológicos y el acceso a recursos naturales y servicios ambientales. Para conectar las variables anteriores, se formuló la siguiente pregunta de investigación: ¿`cuál es el aporte de los CED derivados de la distribución ecológica al desarrollo sostenible en la Cuenca Carbonífera de la Sinifaná a partir de la década de los noventa?

La hipótesis de trabajo es que los CED analizados desde la distribución ecológica están aportando al Ds de la zona. Para dar respuesta a lo anterior, se formularon a su vez los siguientes objetivos: caracterizar la distribución ecológica 
de la cCs a partir del concepto de sistema socio-ecológico y de la Evaluación de Ecosistemas del Milenio de la ONU; identificar los CED en la CCS e interpretar los resultados de los CED articulados a los oDs para determinar las causas de la distribución ecológica en el ecosistema y su incidencia en el Ds de la zona.

El presente artículo se estructura de la siguiente manera: después de esta introducción, se presenta el método y los materiales para realizar la investigación. En la tercera sección, se desarrollan los resultados y en la cuarta se elabora una breve discusión de los mismos, para finalmente cerrar con las conclusiones.

\section{MÉTODO Y MATERIALES}

La etapa práctica de la investigación se realizó bajo un enfoque descriptivo y analítico, con énfasis relacional. Desde la perspectiva descriptiva, se identificaron y se caracterizaron los CED asociados a la distribución ecológica en la CCS, mientras que desde la perspectiva analítica con énfasis relacional, se contrastó la hipótesis de relación entre los CED, la distribución ecológica y los oDs. La integración de estos dos enfoques llevó a la comprensión de la complejidad del estudio de los CED que surgen en torno a la explotación del carbón y el impacto en el Ds de la CCS (véase figura 1).

Para la caracterización de la distribución ecológica, se tomó como referente el Modelo de Evaluación de los Ecosistemas del Milenio (MEem) (ONU, 2003), donde se destaca la interrelación entre las dimensiones a tener en cuenta: servicios de los ecosistemas, bienestar humano e impulsores de cambio directos e indirectos. Además, se señala a la distribución ecológica en términos de la dinámica social-ecológica asociadas a la actividad minera, y a los CED en términos de los beneficios ambientales (véase figura 2).

El trabajo de campo se llevó a cabo en el municipio de Amagá, y se construyó una descripción de la distribución ecológica y de los CED, estructurada en los CED derivados de la distribución ecológica del ecosistema, la identificación de las relaciones de los CED y las transformaciones del ecosistema y el componente del bienestar humano. En la figura 3 se muestran los actores e instituciones que realizaron aportes a los conflictos presentados (véase Anexo, cuadros A1 y A2).

Se realizaron entrevistas y visitas a la zona de estudio (Municipio de Amagá), donde se observó todo el entorno en forma directa, y se participó en la cotidianidad local a detalle sobre su sociedad y su conflicto (véase Anexo). Las entrevistas realizadas fueron hechas directamente a los usuarios de la CCS (véase figura 3). 
Figura 1. Aspectos metodológicos de la investigación

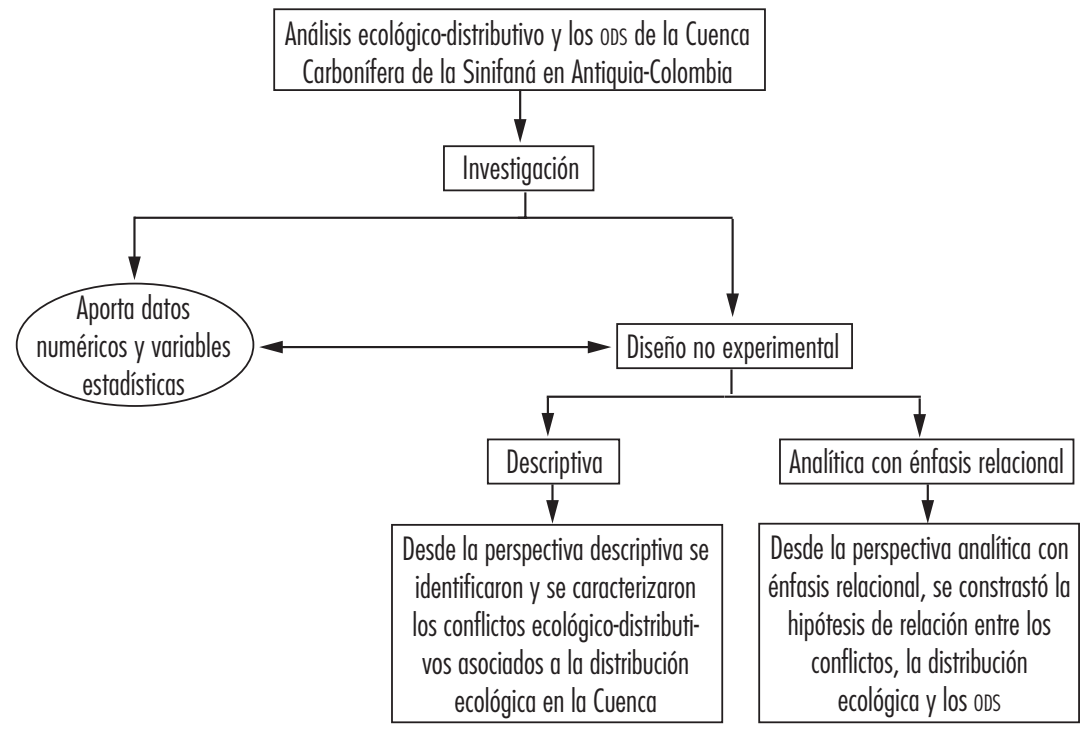

Fuente: elaboración propia.

Figura 2. Aproximación para la caracterización de la distribución ecológica en la cCS

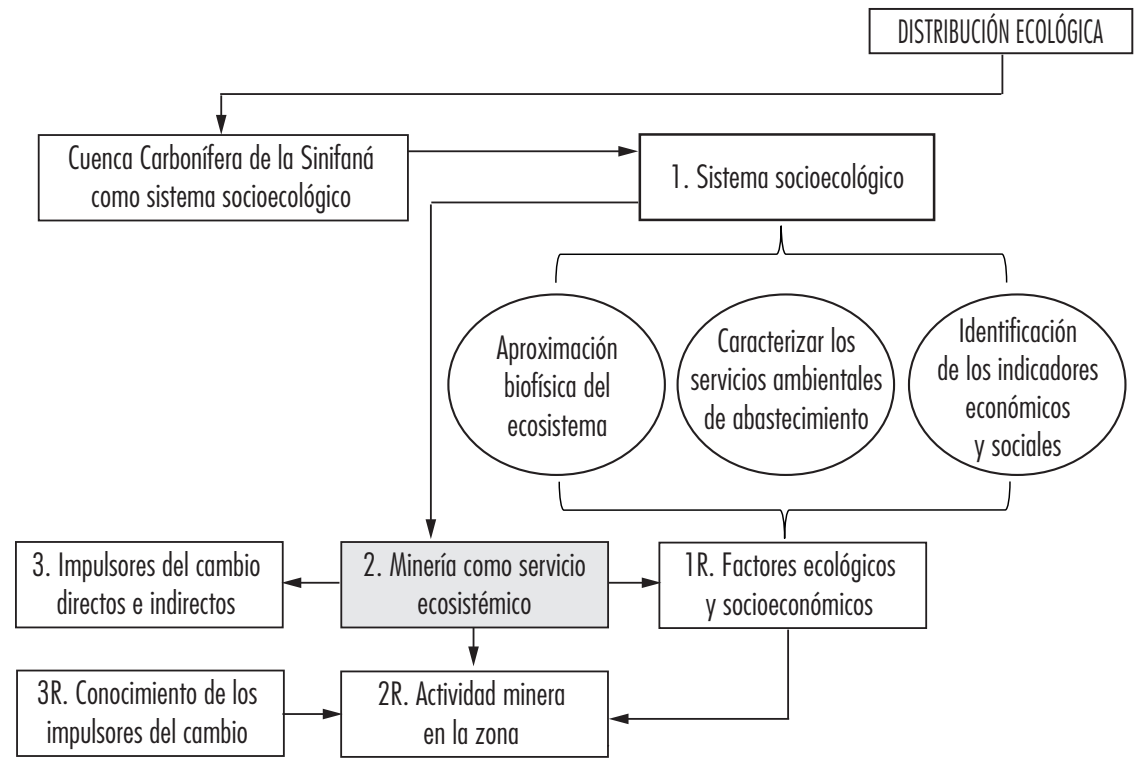

Fuente: elaboración propia. 
Liliana Lotero Álvarez

Figura 3. Usuarios de los servicios ambientales: actores e instituciones

\begin{tabular}{|c|c|c|}
\hline Agentes gubernamentales & $»$ & $\begin{array}{l}\text { Local: alcaldes, inspección de trabajo, consejeros municipales. } \\
\text { Regional: Corantioquia, Secretaría de Minas, SENA. } \\
\text { Nacional: Ingeominas. }\end{array}$ \\
\hline Agentes económicos & $\begin{array}{l}\text { » } \\
»\end{array}$ & $\begin{array}{l}\text { Pequeños mineros. } \\
\text { Grandes mineros. } \\
\text { Intermediarios. }\end{array}$ \\
\hline $\begin{array}{l}\text { Organizaciones comunitarias } \\
\text { o sociales }\end{array}$ & » & $\begin{array}{l}\text { ASomicSI. } \\
\text { Escuela Nacional Sindical. } \\
\text { Periódico El Amagaseño. } \\
\text { Habitantes de Amagá. } \\
\text { Juntas de Acción Comunal. }\end{array}$ \\
\hline $\begin{array}{l}\text { Organizaciones no } \\
\text { guberanamentaes }\end{array}$ & » & $\begin{array}{l}\text { Hogar juvenil campesino y minero. } \\
\text { Fundación Amigos de Amagá. } \\
\text { Ciudad en Bosco. }\end{array}$ \\
\hline
\end{tabular}

Fuente: elaboración propia.

La información se direccionó a indagar en torno a los indicadores de interés relacionados con la explotación del carbón, a contrastar deducciones teóricas acerca de la relación entre los conceptos de la distribución ecológica y los CED, y a identificar relaciones explícitas generadas a partir de la explotación del carbón entre los conflictos y el Ds a partir del equilibrio social, económico y ambiental. Desde la evidencia empírica se construyeron los CED generados en la cCs. Para la consolidación de la información, se contó con los testimonios publicados en prensa y en revistas (véase Anexo, cuadro A1), permitiendo identificar las tendencias generales de los conflictos.

El tamaño de la muestra se construyó con los diferentes actores de agentes gubernamentales, agentes económicos, organizaciones comunitarias, organizaciones no gubernamentales (se realizaron 40 entrevistas, las cuales están caracterizadas en el Anexo, cuadro A1). 


\section{RESULTADOS}

\section{Desarrollo Sostenible y los ODS}

El origen del concepto de DS se remonta a la década de los setenta, como lo expresa Mata (2009, p. 12): "el Desarrollo Sostenible se perfila como concepto por primera vez en el Club de Roma en 1972 aludiendo al vínculo existente entre crecimiento económico global y escasez de recursos naturales". Sin embargo, para autores como Pierri (2005, p. 6): "La introducción de la crisis ambiental en la arena política tuvo lugar a finales de los sesenta. Fue impulsada por la producción de una serie de informes científicos, y tuvo una instancia decisiva en la Conferencia sobre el Medio Humano de la onu realizada en Estocolmo-Suecia".

No obstante, la ONU propuso a la Comisión Brundtland, la cual presentó a la Asamblea General en 1987 un informe que tituló "Nuestro Futuro Común" en el que se acuñó oficialmente el término Ds. Este Informe establece el DS como una política a seguir y su definición se tomó como marco para este artículo: "Desarrollo Sostenible es aquel que satisface las necesidades del presente sin comprometer la capacidad de las futuras generaciones para satisfacer las propias" (Brundtland, 1987, p. 41), así como "un enfoque holístico en el sentido de que la sociedad debe perseguir simultáneamente objetivos económicos, sociales y ambientales" (Sachs, 2016, p. 20).

Dentro de este marco, se realizó la caracterización de los CED y su influencia sobre el Ds en la zona de estudio, con el fin de identificar la satisfacción de las necesidades humanas y la generación de bienestar en la sociedad, a partir del acceso a los beneficios de los recursos naturales y los servicios ambientales de la cCs.

A partir de la configuración de la Agenda 2030 se derivan 17 oDs representados en 169 metas, los cuales fueron creados para llevar a cabo acciones que propicien un camino hacia la consecución del Ds en los países. Con relación a estos oDs, la ONU determina que "el conocimiento de los 17 Objetivos de Desarrollo Sostenible (oDs) asociados a esta Agenda ayuda a evaluar el punto de partida de los países de la región [en este caso los municipios en estudio] y a analizar y formular los medios para alcanzar esta nueva visión del desarrollo sostenible [análisis planteado desde las metas de los oDs], que se expresó de manera colectiva y quedó plasmada en la Agenda 2030" (onU, 2018, p. 5).

Cada ods (véase figura 4) contiene una variedad de temas (metas que sirvieron de guía para identificar los conflictos), es decir, cada oDs es un mundo en sí mismo y no se agota con el nombre de su enunciado, el trabajo de los oDs 
Figura 4. Los 17 Objetivos de Desarrollo Sostenible de la Agenda Global del Desarrollo 2015-2030

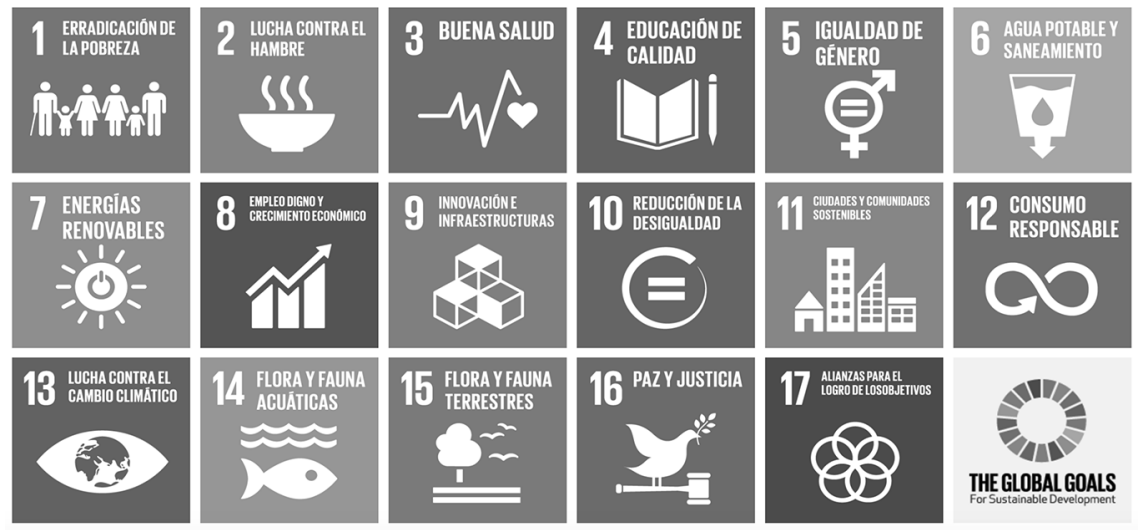

Fuente: ONU (2018).

es interdependiente y cada uno en sus resultados positivos o negativos tienen incidencia sobre los otros (INNOve, 2016).

Dentro de este marco, se presenta la caracterización de los CED analizados desde la distribución ecológica y su influencia sobre el Ds en la zona de estudio, con el fin de identificar la satisfacción de las necesidades humanas y la generación de bienestar en la sociedad, a partir del acceso a los beneficios de los recursos naturales y los servicios ambientales de la CCS y los indicadores económicos, sociales y ambientes de los oDs. El planteamiento anterior, llevó a analizar (a través de las metas de los ODs), los servicios ambientales, en este caso el carbón, si se están generando transformaciones en el ecosistema (conflictos ecológico-distributivos), como resultado de las acciones humanas (distribución ecológica desigual), es decir, si se originaron cambios en los componentes del bienestar humano. Esta identificación dentro de este contexto permitió definir si existen relaciones más sostenibles entre los seres humanos y la naturaleza.

El concepto de distribución ecológica propuesto por Martínez-Alier (2004b), no presenta una elaboración teórica detallada que oriente sus características o manifestaciones. Es por esto que para identificar los indicadores que permitieran la caracterización de la distribución ecológica en la CCS, se realizó un rastreo de conceptos que condujo a adoptar la Evaluación de Ecosistemas del Milenio de la Organización de las Naciones Unidas (EM) la cual es un "programa internacional diseñado para satisfacer las necesidades que tienen los encargados de la toma de decisiones de contar con información 
sobre los vínculos entre el cambio de los ecosistemas y el bienestar humano" (ONU, 2003, p. 5).

Sus conclusiones proporcionaron una valoración científica sobre la condición y las tendencias en los ecosistemas mundiales, los servicios que proveen y las opciones para restaurar, conservar o mejorar el uso (onU, 2003, p. 11). El análisis de los indicadores bajo la EM proporcionó una valoración que condujo a deducir la validez para el presente artículo, en términos de las categorías que lo integran: social, económica y ambiental. Además, con una explícita consideración del contexto espacial y temporal (véase figura 5).

Como se puede ver en la figura 5, la lista de beneficios o prestaciones que propone la EM es diversa, no obstante, para la investigación se puso énfasis en los servicios de suministro o abastecimiento que "son los productos que las personas adquieren de los ecosistemas: alimentos, combustibles, fibras, agua pura [recursos energéticos]" (ONU, 2003, p. 13), donde se aprecia a la minería del carbón como servicio ecosistémico, como un recurso finito y no renovable.

Sobre las consideraciones anteriores, se tomó desde la EM, los sistemas socio-ecológicos que proveen un marco para considerar de forma integrada las dimensiones ecológica y social, así como sus interrelaciones (Ostrom, 2009, p. 2). Estos sistemas "se caracterizan por ser sistemas complejos adaptativos en los que los componentes sociales y ecológicos están acoplados [...]. El sistema natural se relaciona con el sistema social por medio de los servicios que ofrecen los ecosistemas, que contribuyen a satisfacer las necesidades humanas y generan bienestar" (Vilardy et al., 2011, p. 19).

Dicho lo anterior, se considera la cCs y su entorno como un sistema socioecológico, por cuanto "integra la naturaleza, el aprovechamiento que se hace de ella, la sociedad y las instituciones como un todo que interactúa de manera dinámica en el tiempo y en el espacio" (Vilardy et al., 2011, p. 19). Para el conocimiento del sistema socio-ecológico (véase figura 6) y su dinámica, se analizaron las relaciones entre la sociedad y su entorno; por tanto, esta información "permite reconstruir los procesos que han generado los problemas ambientales [económicos] e identificar el patrón de cambios y respuestas adaptativas del sistema ante esos cambios, lo que facilita el análisis de las posibles respuestas futuras" (Walker et al., 2004; Berkes et al., 2003; González et al., 2008 citado por Vilardy y Renán (2011, p. 109)). 


\section{Liliana Lotero Álvarez}

Figura 5. Marco conceptual de la Evaluación de los Ecosistemas del Milenio

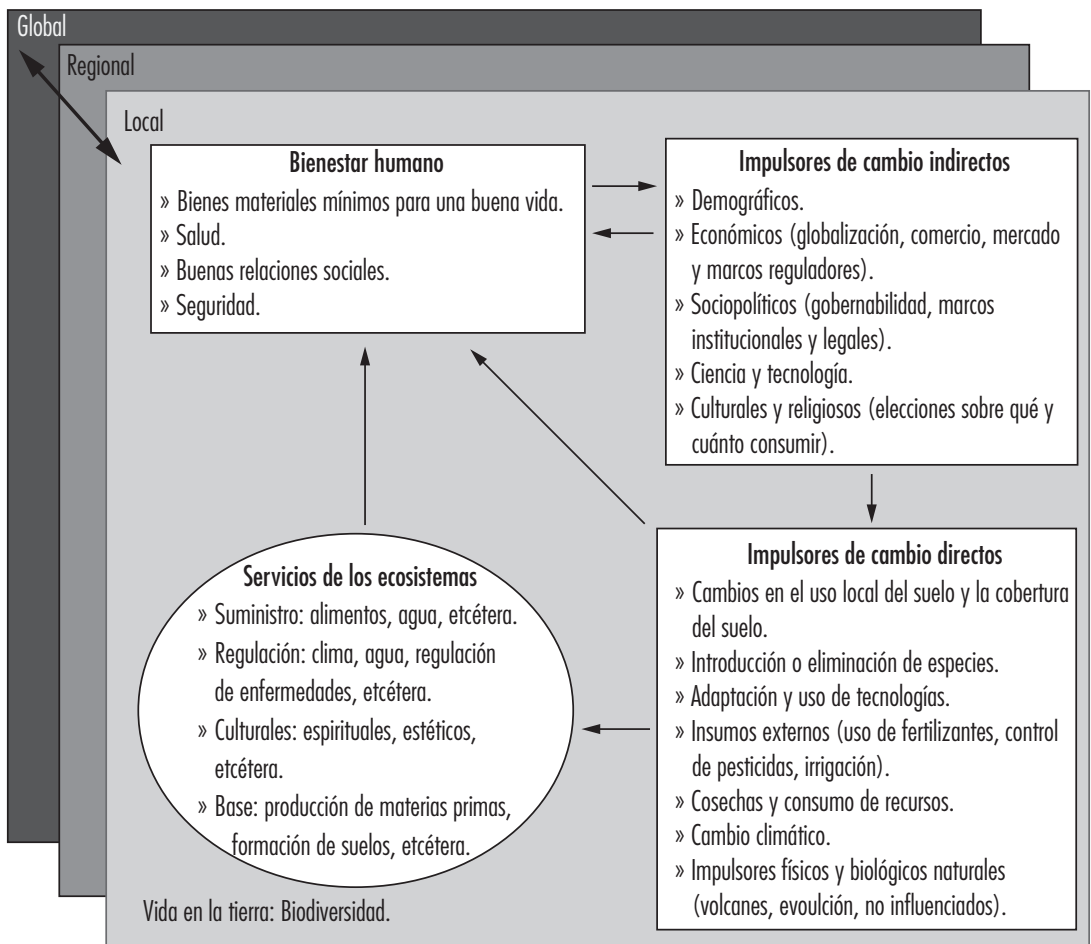

Fuente: evaluación de los Ecosistemas del Milenio (ONU, 2003).

\section{Figura 6. Sistema socio-ecológico}

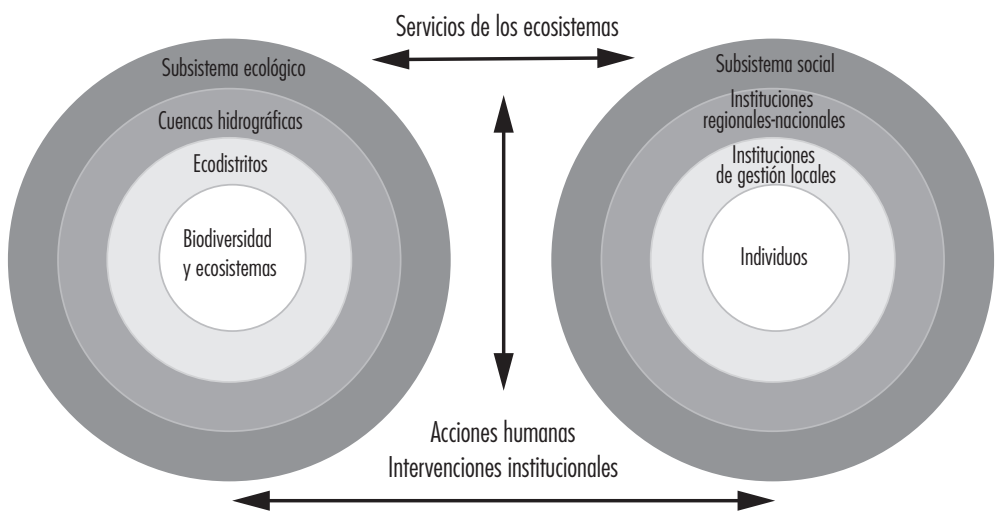

Fuente: Martín-López et al. (2009). Adaptación propia. 
Como resultado del análisis, se dedujo toda la composición de la distribucion ecológica en la CCS, y se definieron las relaciones del sistema social con el sistema natural; es decir, la interacción dinámica de los ecosistemas con las poblaciones humanas y el resultado de las acciones humanas, que "por un lado, actúan impulsando transformaciones en los ecosistemas [distribución ecológica desigual] y, por otro, las modificaciones en los ecosistemas provocan cambios en los distintos componentes del bienestar humano [desarrollo sostenible]" (Vilardy et al., 2011, p. 49). Estos componentes de bienestar humano se asociaron con "el concepto de necesidades en particular necesidades esenciales de los pobres a las que debían otorgar prioridad preponderante” (Brundtland, 1987, p. 67).

Para analizar los Ced se asumió la definición de Martínez-Alier (2004b, p. 2): "los conflictos que surgen de una distribución ecológica desigual o al empeorar la distribución ecológica [...]”, que manifiesta que es tema común, el estudio de los conflictos sociales relacionados con el acceso a los recursos y a los servicios ambientales y su destrucción (Martínez-Alier, 2001, p. 1). Así entonces Lamberti (2010, p. 307), por su parte, plantea que "estos conflictos al involucrar también lenguajes de valoración no pueden estudiarse únicamente desde la teoría económica, por ello es necesario partir de perspectivas interdisciplinarias como la Ecología Política”.

La Ecología Política presenta una mirada integral de los conflictos ambientales, donde distintos actores que tienen distintos intereses, valores, culturas y saberes, usan o pueden usar distintos lenguajes de valoración (Martínez-Alier, 2009, p. 8). Dentro de este marco, Fisher et al., citado por Vilardy et al. (2011, p. 49) menciona "que los servicios de los ecosistemas son los beneficios que provee el ecosistema que contribuyen al bienestar humano, los cuales pueden ser utilizados activa o pasivamente". La forma de utilización de estos servicios afecta de diversas maneras el bienestar humano (onU, 2003, p. 13), esto se entiende como "los cambios que afectan el bienestar humano [derivados de una distribución ecológica desigual] a través de los impactos en la seguridad, las necesidades materiales básicas para el buen vivir, la salud y las relaciones sociales y culturales" (ONU, 2003, p. 14) y la cCs, como ecosistema, proporciona diversos beneficios al bienestar humano. Del planteamiento anterior, se deriva la relación de las diferentes variables (véase figura 7). 
Figura 7. Relación de los impactos directos e indirectos, los conflictos ecológico-distributivos y el bienestar humano para un DS

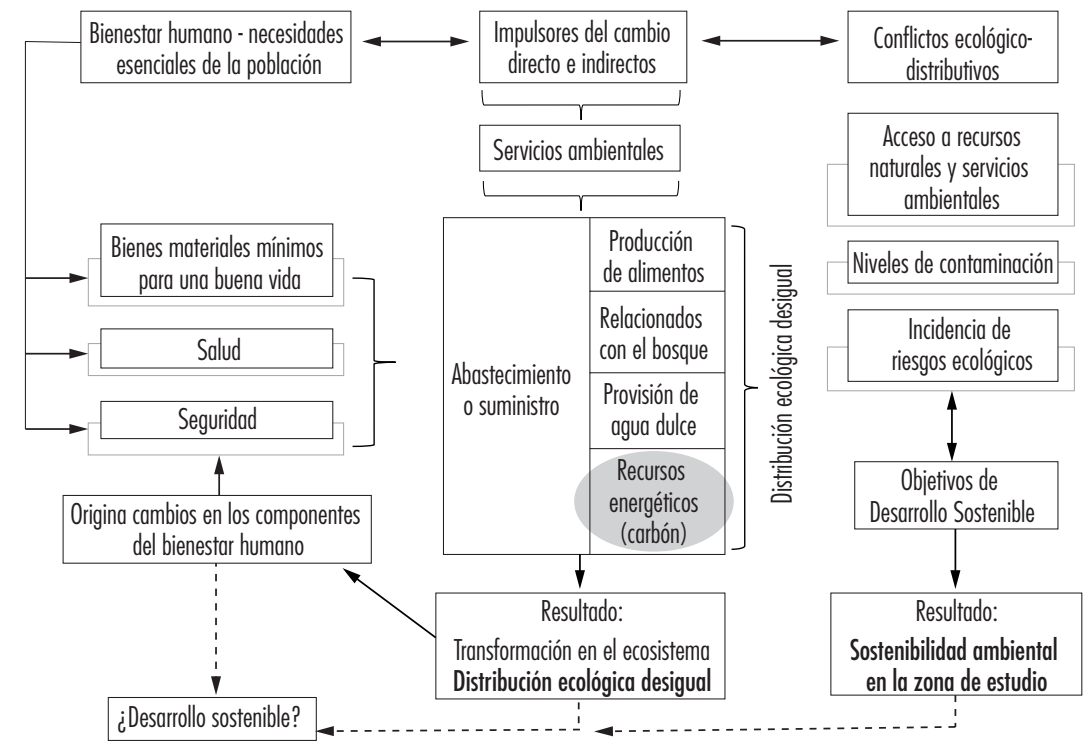

Fuente: elaboración propia.

\section{Distribución ecológica y servicios ambientales de la CCS}

Con relación a la figura 7, el estudio se basó en los servicios de abastecimiento (carbón), haciendo énfasis en el municipio de Amagá y Titiribí con 16.001 y 84.229 toneladas de producción de carbón durante 2017 (sIMco, 2017), lo cual lo convierte en su principal actividad económica, así como proveedores de los mayores cambios originados en el ecosistema (véase Anexo). La explotación del carbón para los habitantes de la Cuenca es la fuente de ingresos económicos más importante, pues de esta actividad se deriva su mayor ingreso familiar. Es por esta razón, que en los últimos años se ha generado un aumento de minas de carbón que se relacionan directamente con la demanda interna y nacional actual del mineral, además con el escaso conocimiento geológico (véase Anexo). Esta explotación de carbón, como servicio ambiental, es intercalada con otros servicios que surte el ecosistema.

Dentro de las demás actividades productivas como beneficios ambientales surtidos por la CCs, destaca la producción agrícola (véase cuadro 1); sin embargo, en el municipio de Amagá, al día de hoy, la producción de carbón sobresale sobre el cultivo de café que ha sido uno de los conflictos económicos 
generado por la falta de tierras para cultivar, el deterioro del suelo y el uso de fincas de recreo (véase Anexo). Alterno al cultivo del café, se encuentra el cultivo de plátano, de aguacate y de naranja en menor proporción, ya que se encuentran aislados por su poca importancia comercial (véase cuadro 1). La producción agrícola, pecuaria y forestal (BIRD, 2011), como servicios ambientales, han visto disminuida su participación como actividad económica, dada la preferencia de los habitantes a trabajar en la explotación de carbón (Amagá y Angelópolis), expresado por los alcaldes, los cuales manifiestan que el mayor sustento económico de las familias de los municipios es derivado de la explotación del carbón (véase Anexo).

Esta desigual apropiación y uso de los servicios ambientales, generan conflictos ambientales asociados a los daños en la superficie del suelo y a la cobertura vegetal, generan emisión de partículas a la atmósfera al momento de realizarse las voladuras (Najera et al., 2011), la disminución de la calidad del agua se encuentra dentro del nivel de naturaleza negativa e impacto medio (Corantioquia, 2007), causada por las deficientes prácticas de la minería ilegal e informal o tradicional, que cada día va en aumento, según la Asociación Nacional de Industriales (ANDI, 2010): "en materia ambiental el mayor problema está asociado con las prácticas insostenibles de la minería ilegal” (véase Anexo).

Lo anterior es originado, por las descargas de aguas ácidas y con alto contenido de sólidos que al ser vertidas sin tratamiento afectan la fauna que habita en los cuerpos de agua que las reciben (Corantioquia, 2007, p. 125). A escala temporal, estos efectos ambientales se aprovechan a corto, mediano y largo plazo, dependiendo del tipo de servicio ecosistémico. A escala espacial, el aprovechamiento es local, debido a que son servicios que se presentan en la misma zona. La distribución de los beneficios es diferencial y provocan cambios en los diferentes componentes del bienestar humano.

Para la caracterización de la distribución ecológica, se definieron los impulsores del cambio que son los factores que alteran el ecosistema; estos impulsores son importantes para determinar cuál es el origen de las transformaciones que está sufriendo el ecosistema; es decir, establecer cuáles son los CED que están generando cambios en el ecosistema y son el impulsor directo que influye en los procesos del ecosistema y el impulsor indirecto que opera, alterando uno o más impulsores directos. Los impulsores directos como los indirectos por lo general operan sinérgicamente (oNU, 2003, p. 22). La interacción de varios de estos impulsores afectan los niveles de consumo de los recursos y la participación en el consumo de la sociedad. A continuación, se describen los principales impulsores del cambio presentes en la ccs y la escala espacial en la cual se desarrollan (véase cuadro 2). 


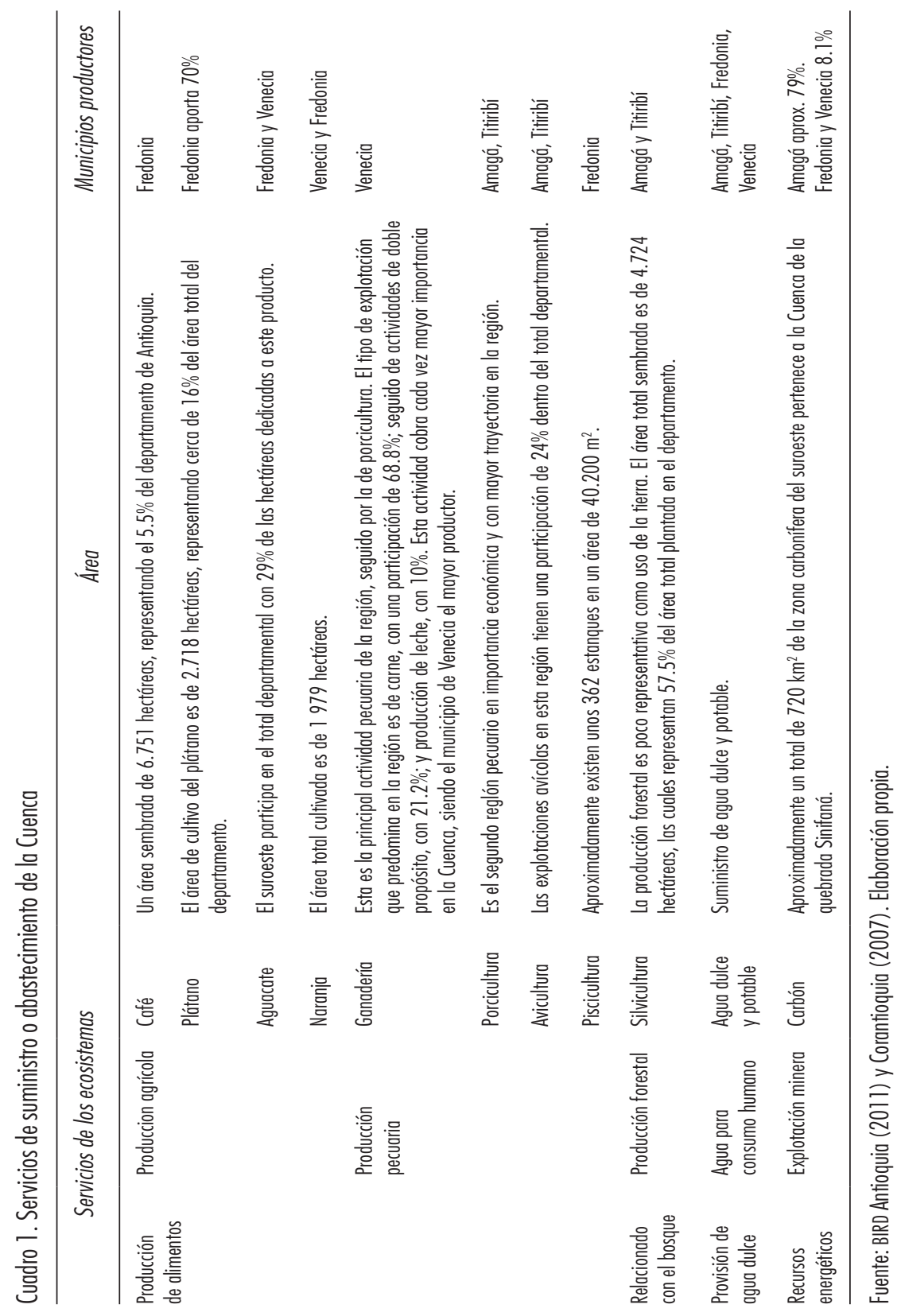


Cuadro 2. Impulsores del cambio directo e indirecto. Tipo: suministro o abastecimiento

\begin{tabular}{|c|c|c|}
\hline Impulsores & Descripción & Espacial \\
\hline $\begin{array}{l}\text { Demográficos - } \\
\text { crecimiento de } \\
\text { la población }\end{array}$ & $\begin{array}{l}\text { La población de la ccs ha venido en aumento. En la tasa de } \\
\text { crecimiento intercensal la población promedio pasa de 1985-1993 } \\
\text { a 1993-2005 de } 0.30 \text { a 0.38\%, respectivamente, en los cinco } \\
\text { municipios. Además hay una población flotante que se desplaza por } \\
\text { las distintas minas de la región, lo que ha hecho que haya una gran } \\
\text { concentración de población en las zonas donde hay mayor explotación } \\
\text { de carbón, en este caso el municipio de Amagá. }\end{array}$ & $\begin{array}{l}\text { En cuanto a la densidad poblacional, el } \\
\text { municipio de Amagá presenta la mayor } \\
\text { densidad con un total de } 338 \text { habitantes } \\
\text { por } \mathrm{km}^{2} \text {. Siguiéndole Angelópolis y } \\
\text { Venecia con } 95 \mathrm{~km}^{2} \text {. Además de la } \\
\text { escala local, también se presenta a nivel } \\
\text { nacional e internacional. }\end{array}$ \\
\hline \multirow[t]{3}{*}{$\begin{array}{l}\text { Económicos - } \\
\text { boom minero } \\
\text { carbonífero }\end{array}$} & $\begin{array}{l}\text { Con la tendencia presentada en la explotación de carbón a nivel } \\
\text { internacional, ha aumentado y se ha dado por tres motivos: a) } \\
\text { Demanda de energía originada por los paises desarrollados y algunos } \\
\text { en vías de desarrollo; b) Favorabilidad en los precios internacionales } \\
\text { del carbón; c) Beneficios para la explotación en los países productores. }\end{array}$ & Internacional, nacional y local. \\
\hline & Sobreexplotación de minería ilegal. & $\begin{array}{l}\text { Internacional y toda la Cuenca } \\
\text { Carbonífera de la Sinifaná. }\end{array}$ \\
\hline & Precios del carbón y el mercado carbonífero. & Internacional, nacional y local. \\
\hline \multirow[t]{2}{*}{ Sociopolíticos } & Legislación ambiental y minera internacional y nacional. & Internacional y nacional. \\
\hline & $\begin{array}{l}\text { Políticas macroeconómicas relacionadas con la explotación } \\
\text { de los recursos naturales. }\end{array}$ & Todo el territorio nacional. \\
\hline \multirow[t]{2}{*}{$\begin{array}{l}\text { Degradación } \\
\text { del suelo }\end{array}$} & $\begin{array}{l}\text { Degradación de suelos por factor de pluviosidad y uso inadecuado } \\
\text { del suelo. }\end{array}$ & Toda la Cuenca de la Sinifaná. \\
\hline & Sistemas de producción tipo extensivo de la ganadería. & Toda la Cuenca de la Sinifaná. \\
\hline $\begin{array}{l}\text { Contaminación } \\
\text { del agua }\end{array}$ & $\begin{array}{l}\text { Por la práctica minera y la falta de control en la explotación de la } \\
\text { minería ilegal, se está presentando aumento en la contaminación de } \\
\text { las aguas que surte la cuenca hidrográfica de la Sinifaná. }\end{array}$ & $\begin{array}{l}\text { En Amagá donde se encuentra la mayor } \\
\text { explotación de carbón. }\end{array}$ \\
\hline
\end{tabular}

Fuente: elaboración propia a partir de datos de fuentes primarias (véase Anexo) y Corantioquia (2007).

Del cuadro 2 se desprende que existen transformaciones realizadas al ecosistema y que se establecen como impulsores: el crecimiento de la población, la demanda de energía, los precios internacionales del carbón, la normatividad ambiental y minera, las políticas macroeconómicas, entre otras, que deducen los indicadores clave que originan los CED que afectan el acceso, uso o apropiación de los beneficios de los recursos naturales y los servicios ambientales, aunado a los cambios ocasionados por las acciones humanas que se ven reflejados a través de la degradación del suelo y la contaminación del agua.

A continuación, se describen los CED que se derivan de la desigualdad ecológica generada en los servicios de suministro o abastecimiento de la CCs. 


\section{La minería carbonífera y los CED}

Como resultado del análisis de los servicios de suministro o abastecimiento de la CCS, los impulsores y la evidencia empírica (véase Anexo), los CED que se derivan son los siguientes:

\section{Conflictos de corte socioeconómicos}

En el cuadro 3, los usuarios los clasifican como de mayor relevancia para la problemática presentada en la CCs (véase Anexo).

Cuadro 3. Conflictos de corte socioeconómico y ambiental en la ccS

\begin{tabular}{|c|c|c|c|}
\hline $\begin{array}{l}\text { Medio } \\
\text { afectado }\end{array}$ & $\begin{array}{c}\text { Conflictos que se } \\
\text { presentan en la Cuenca }\end{array}$ & $\begin{array}{l}\text { Problemas ambientales } \\
\text { en la minería carbonífera }\end{array}$ & Fuente del impacto \\
\hline \multirow[t]{15}{*}{ Físico-biótico } & - Disminución de la calidad del aire. & Emisión de partículas fugitivas. & - Corantioquia (2006). \\
\hline & & Emisión de gases. & \multirow{14}{*}{$\begin{array}{l}\text { - Gobernación de } \\
\text { Antioquia (2007). }\end{array}$} \\
\hline & - Disminución de la calidad del agua. & Contaminación físico-química. & \\
\hline & - Alteración de los drenajes. & & \\
\hline & - Mal manejo de aguas residuales. & & \\
\hline & - Inadecuada disposición de residuos. & $\begin{array}{l}\text { Contaminación biológica y con } \\
\text { materia orgánica. }\end{array}$ & \\
\hline & $\begin{array}{l}\text { - Mal estado de las redes de acueducto y } \\
\text { alcantarillado existentes. }\end{array}$ & Obstrucción de cauces naturales. & \\
\hline & $\begin{array}{l}\text { - Contaminación hídrica: agua no apta para } \\
\text { el consumo humano. }\end{array}$ & Aporte de sedimentos a corrientes. & \\
\hline & - Cambio en las características edáficas. & \multirow{3}{*}{$\begin{array}{l}\text { Cambios en propiedades físico- } \\
\text { químicas. }\end{array}$} & \\
\hline & - Subsidencia e inestabilidad del suelo. & & \\
\hline & - Contaminación y degradación del suelo. & & \\
\hline & $\begin{array}{l}\text { - Cambios en el uso del suelo hacia } \\
\text { parcelaciones uso inadecuado del suelo. }\end{array}$ & Subsidencia. & \\
\hline & - Procesos erosivos: degradación del suelo. & $\begin{array}{l}\text { Pérdida de capa orgánica e } \\
\text { inorgánica. }\end{array}$ & \\
\hline & - Activación de procesos erosivos. & Tala arbórea. & \\
\hline & $\begin{array}{l}\text { - Tala arbórea y pérdida de la cobertura } \\
\text { vegetal. }\end{array}$ & Reducción de cobertura vegetal. & \\
\hline
\end{tabular}




\begin{tabular}{|c|c|c|c|}
\hline $\begin{array}{l}\text { Medio } \\
\text { afectado }\end{array}$ & $\begin{array}{c}\text { Conflictos que se } \\
\text { presentan en la Cuenca }\end{array}$ & $\begin{array}{l}\text { Problemas ambientales } \\
\text { en la minería carbonífera }\end{array}$ & Fuente del impacto \\
\hline Físico-biótico & $\begin{array}{l}\text { - Alteración del hábitat y de los ecosistemas } \\
\text { fluviales. }\end{array}$ & Alteración de hábitat. & \\
\hline \multirow[t]{8}{*}{ Socioeconómico } & $\begin{array}{l}\text { - Incremento del nivel de empleo y efecto } \\
\text { sobre otras actividades. } \\
\text { - Disminución de la producción pecuaria y } \\
\text { agrícola. }\end{array}$ & Generación de empleo. & $\begin{array}{l}\text { - Corantioquia (2006). } \\
\text { - Testimonios, } 2012 .\end{array}$ \\
\hline & $\begin{array}{l}\text { - Aumento de ingresos. } \\
\text { - Necesidad de generación de ingresos para la } \\
\text { subsistencia familiar. }\end{array}$ & Incremento del nivel de ingresos. & \\
\hline & $\begin{array}{l}\text { - Cadena de intermediación / comercialización } \\
\text { del carbón. }\end{array}$ & Comercialización del carbón. & \\
\hline & $\begin{array}{l}\text { - Deterioro de las condiciones ergonómicas y } \\
\text { de salud. } \\
\text { - Aumento del riesgo de accidentalidad, por } \\
\text { incumplimiento en la reglamentación de } \\
\text { seguridad e higiene industrial. }\end{array}$ & Aumento riesgo de accidentalidad. & $\begin{array}{l}\text { - Departamento } \\
\text { Administrativo de } \\
\text { Planeación-2012. } \\
\text { - Secretaria de Minas } \\
\text { Testimonio. } \\
\text { - Corantioquia (2006). }\end{array}$ \\
\hline & $\begin{array}{l}\text { - Falta de aplicación de la normatividad } \\
\text { minera, en cuanto a cumplimiento con los } \\
\text { compromisos relacionados con la seguridad } \\
\text { social. }\end{array}$ & & \\
\hline & $\begin{array}{l}\text { - Falta de acompañamiento por parte de } \\
\text { los entes gubernamentales y deficiente } \\
\text { formulación de la normatividad minera a los } \\
\text { pequeños mineros. }\end{array}$ & & \\
\hline & $\begin{array}{l}\text { - Deficiente apoyo en la formulación de } \\
\text { políticas, por parte del Estado, a los grupos } \\
\text { vulnerables (niños, mujeres y adultos } \\
\text { mayores). }\end{array}$ & & \\
\hline & $\begin{array}{l}\text { - Servicios deficientes en cuanto a salud, } \\
\text { educación, vivienda y servicios públicos. }\end{array}$ & $\begin{array}{l}\text { Necesidades básicas de la } \\
\text { población. }\end{array}$ & \\
\hline
\end{tabular}

Fuente: Testimonios (Anexo) y Corantioquia (2006, 2007), Departamento Administrativo de Planeación (2012).

Se puede corroborar un conflicto determinante, la necesidad de obtener ingresos económicos sin tener en cuenta la seguridad social y minera en los procesos de explotación, es decir, que la protección de la vida pasa a un segundo plano. Según testimonios de las personas del común (véase Anexo): "Desafortunadamente en el municipio aún no hay conciencia sobre el tema de la seguridad minera, por lo que se viene trabajando con los mineros para que 
se organicen, legalicen y cumplan la normatividad sobre seguridad minera"; siguiendo con los testimonios: "las condiciones de seguridad en las minas de carbón en el municipio son muy diversas, y persisten los grandes riesgos para la explotación de esos minerales, especialmente por el gran número de socavones y minas que aún trabajan en la informalidad".

Aunado a lo anterior, no hay una conciencia de una explotación minera con buenas prácticas, es decir, con respeto al medio ambiente y a la vida, debido a que la tradición y las formas de explotación ancestral tienen más peso y valor que cualquier práctica (véase Anexo). El medio ambiente es nuevo para los propietarios de las minas y los mineros, y es una nueva preocupación. Por tanto, aún no está dentro de sus prioridades, según un trabajador minero (véase Anexo): "La minería nuestra es poco sofisticada, pero la estamos trabajando con buenos montajes, los mineros tienen su linterna, ya no es con velas. Hay menos accidentes que antes. Hemos fallado en cosas, pero ahora estamos tratando de hacer las cosas bien". Sumados a estos conflictos, los actores mineros (véase Anexo) encuentran que se derivan los siguientes:

- Falta de aplicación de la normatividad minera y ambiental, incumplimiento en los compromisos relacionados con la seguridad social, según la Dirección de Seguridad y Salvamento Minero: "Hay un error en la interpretación del decreto. La norma prohíbe que las mujeres trabajen bajo tierra, pero no fuera de la mina, donde pueden desempeñar cualquier tipo de tarea. Además, el decreto dice que las mujeres sólo pueden trabajar en dirección y supervisión, se refiere a las que eventualmente desarrollan sus labores dentro del socavón, como las ingenieras y las profesionales de la seguridad".

- Falta de aplicación de la normatividad minera y ambiental, seguridad e higiene industrial, según trabajador minero: "La Alcaldía de Amagá ha luchado por acabar con la minería ilegal a través de seguimientos y capacitaciones con el sENA. El problema es que a los menores de edad es muy difícil frenarlos y sobre todo cuando se está muriendo de hambre. Las gurreras son las más peligrosas por el mal mantenimiento y la falta de garantías que les ofrecen a los trabajadores".

- Falta de acompañamiento a los pequeños mineros por parte de los entes gubernamentales, según abogado especialista en minas: "La ley colombiana eliminó las diferencias en las diferentes modalidades de minería, sometiéndolas a igualdad de condiciones; se fijó un nuevo esquema a través de la figura de la concesión, incluso en áreas de Reserva Minera Especial y se transfirió su autoridad a Municipios y Departamentos". 


\section{Conflictos de corte ambiental}

Para complementar el mapa de conflictos en la zona, se presentaron los CED de corte ambiental (véase cuadro 3), permitiendo reconocer las consecuencias sobre daños ambientales de mayor magnitud. Estos conflictos impactan en mayor proporción a el agua, el aire y el suelo. Según la ANDI:

En materia ambiental el mayor problema está asociado con las prácticas insostenibles de la minería ilegal; un cuestionamiento evidente es la imposibilidad en unos casos y la negligencia en otros, de muchas autoridades ambientales regionales, con respecto a la minería ilegal, lo que hace necesario abrir el debate sobre la estructura, conformación de sus consejos directivos, obligaciones, funciones y sistemas de reporte.

Así entonces Corantioquia (organismo gubernamental ambiental) y la Gobernación de Antioquia, definen como los mayores problemas ambientales (véase cuadro 3): la disminución de la calidad del aire y el agua; la inadecuada disposición de residuos, el cambio en las características edáficas, la subsidencia e inestabilidad del suelo; de acuerdo con el docente de la Universidad de Antioquia (véase Anexo): "Hoy los mineros que, a pesar de que no son formales y que se les considera ilegales, vienen avanzando en mejorar el sistema de medición y control de gases. La técnica de martillo percutor es la que más impacta por el uso de combustible, pero es la más competitiva”.

A escala espacial, en donde los cambios que se originan en el ecosistema tienen origen a escala local, tiene impactos sobre los servicios ambientales, descritos anteriormente como (producción agrícola y pecuaria, pérdida de bosques, disponibilidad de agua para consumo humano), según persona del común (véase Anexo): “Toda la vida gira en torno a la minería. No nos queda más destino que ir al huequito (la mina), en la agricultura no hay nada que hacer, para llevar la comida a la casa [...]".

\section{Los CED y los ODS}

Después de analizar los CED derivados de la distribución ecológica desigual, se contrastaron con las metas e indicadores globales de los oDs, determinando que los ods $(1,2,3,4,5,6,810,11,12,13,15)$ se articularían con los conflictos. En el cuadro 3 se identifica que a partir de los conflictos generados por la explotación minera, no se dan cumplimiento a los oDs. En particular conflictos como: 
- Falta de aplicación de la normatividad minera y ambiental, seguridad e higiene industrial y la seguridad social. Este conflicto no permite el cumplimiento de los ods 1 "Fin de la Pobreza" y 8 "Trabajo decente y crecimiento económico", ya que no garantiza la cobertura de protección social para los pobres y vulnerables ni garantiza que haya acceso a recursos económicos y servicios básicos para la población de la cCs, según la meta 8.8. "Proteger los derechos laborales y promover un entorno de trabajo seguro y sin riesgos para todos los trabajadores, incluidos los trabajadores migrantes, en particular las mujeres migrantes y las personas con empleos precarios (véase cuadro 4).

- Falta de acompańamiento a los pequeños mineros por parte de los entes gubernamentales, este conflicto no permite el cumplimiento del ods 8 "Trabajo decente y crecimiento económico", ya que el Estado no garantiza un entorno de trabajo seguro y protegido a los mineros de la zona (véase cuadro 4). Según la meta 8.5. "De aquí a 2030, lograr el empleo pleno y productivo y el trabajo decente para todas las mujeres y los hombres, incluidos los jóvenes y las personas con discapacidad, así como la igualdad de remuneración por trabajo de igual valor".

- Necesidad de generación de ingresos para la subsistencia familiar, este conflicto no permite el cumplimiento del oDs 10 "Reducción de las desigualdades", ya que establece que haya un crecimiento del ingreso de la población más pobre en la zona de estudio (véase cuadro 4). Según la meta 10.2. "De aquí a 2030, potenciar y promover la inclusión social, económica y política de todas las personas, independientemente de su edad, sexo, discapacidad, raza, etnia, origen, religión o situación económica u otra condición”.

- Los problemas ambientales son disminución de la calidad del aire y el agua; inadecuada disposición de residuos, cambio en las características edáficas, subsidencia e inestabilidad del suelo, lo que no permite el cumplimiento de los ons 3 "Salud y bienestar" que establece que se debe evitar la contaminación del agua, aire y suelo, ods 6 "Agua limpia y saneamiento" manifiesta un uso eficiente de los recursos hídricos en todos los sectores y ods 15 "Vida de Ecosistemas Terrestres" que se direcciona hacia la conservación, el restablecimiento y el uso de los ecosistemas terrestres (véase cuadro 4).

En síntesis, los CED generados en la explotación del carbón no llevan a contribuir al cumplimiento de los ods centrales que son ods 1 "Fin de la pobreza" en el caso de los conflictos socioeconómicos y ods 13 "Acción por el clima" ocasionado por los conflictos ambientales. 


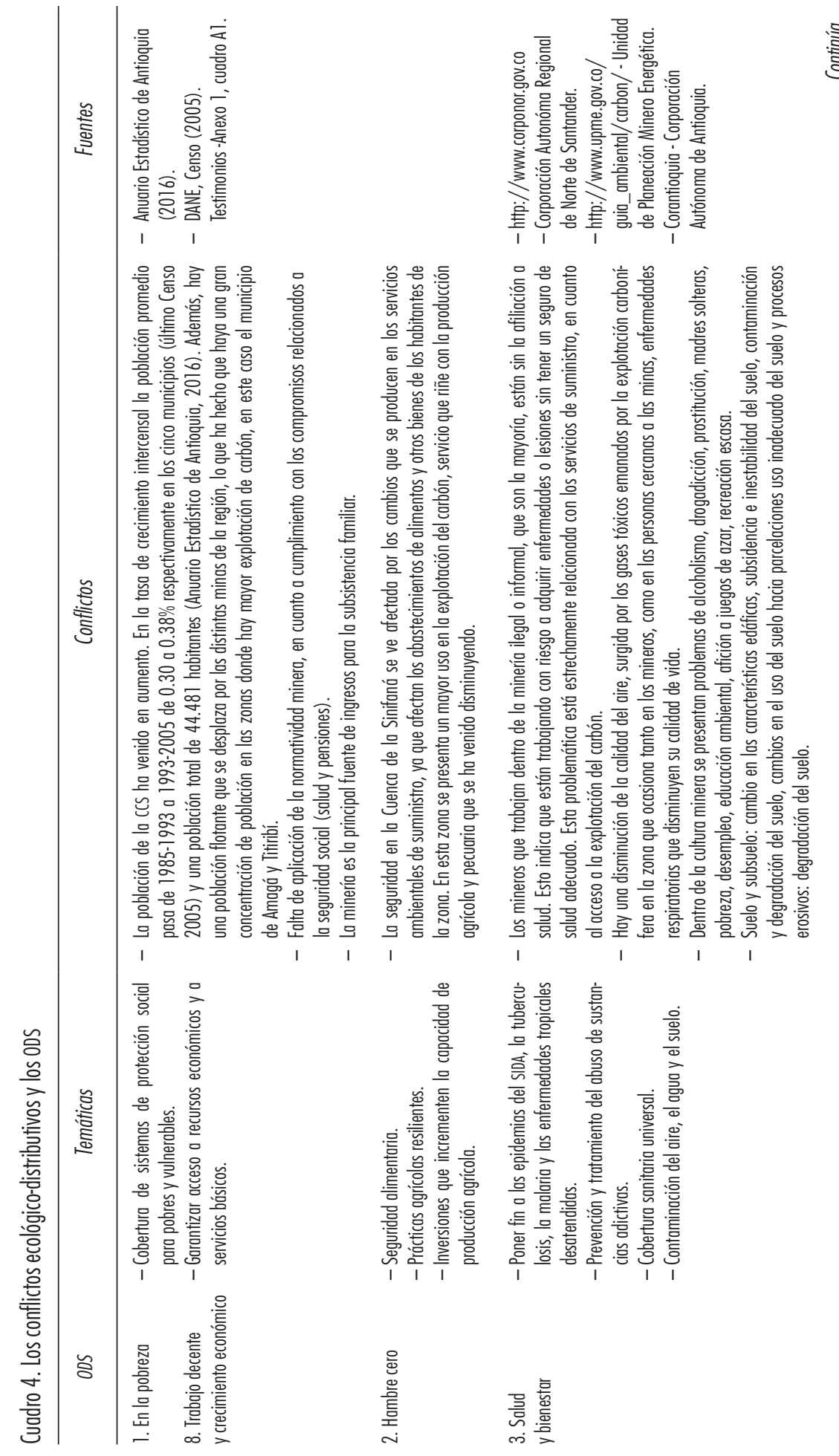




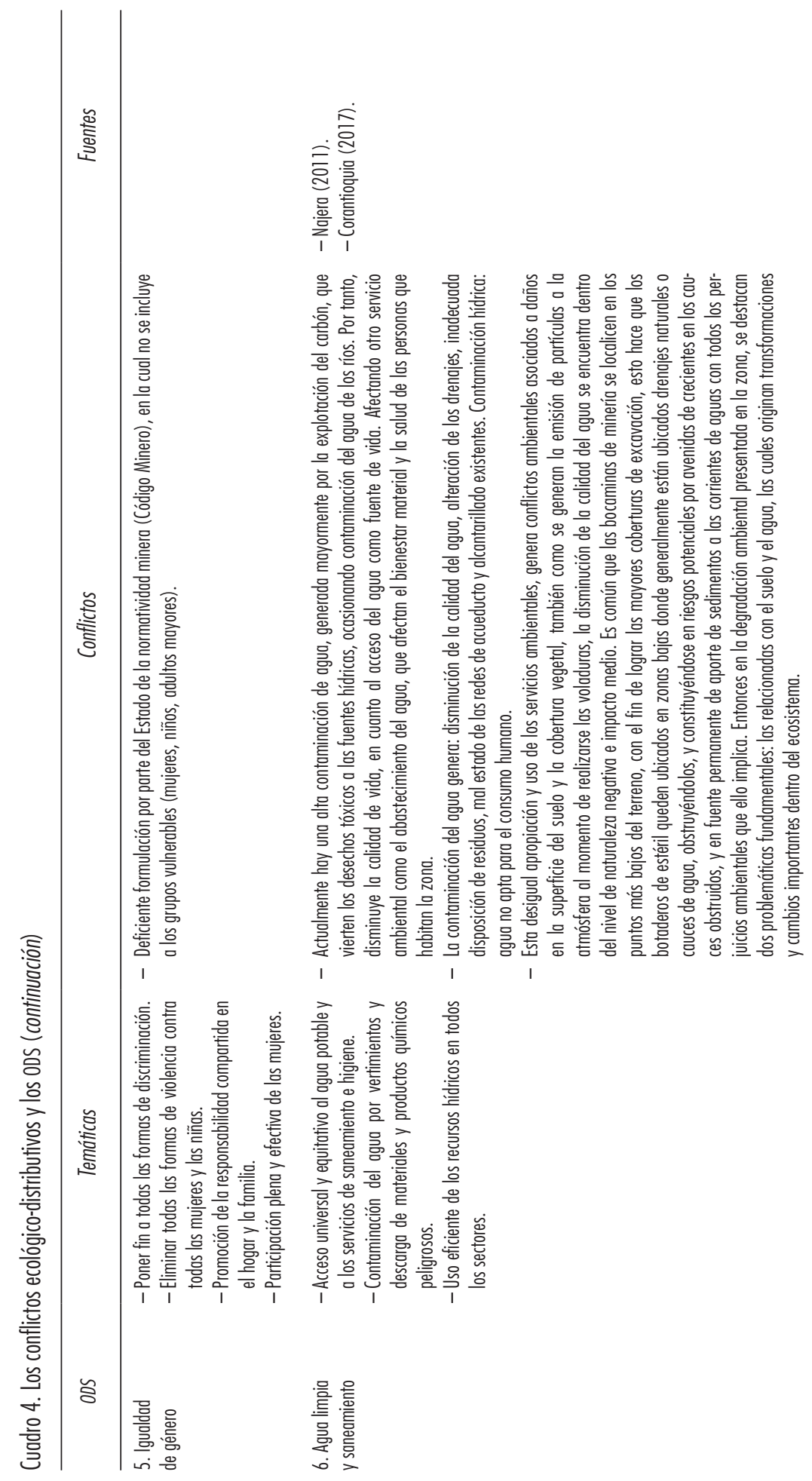




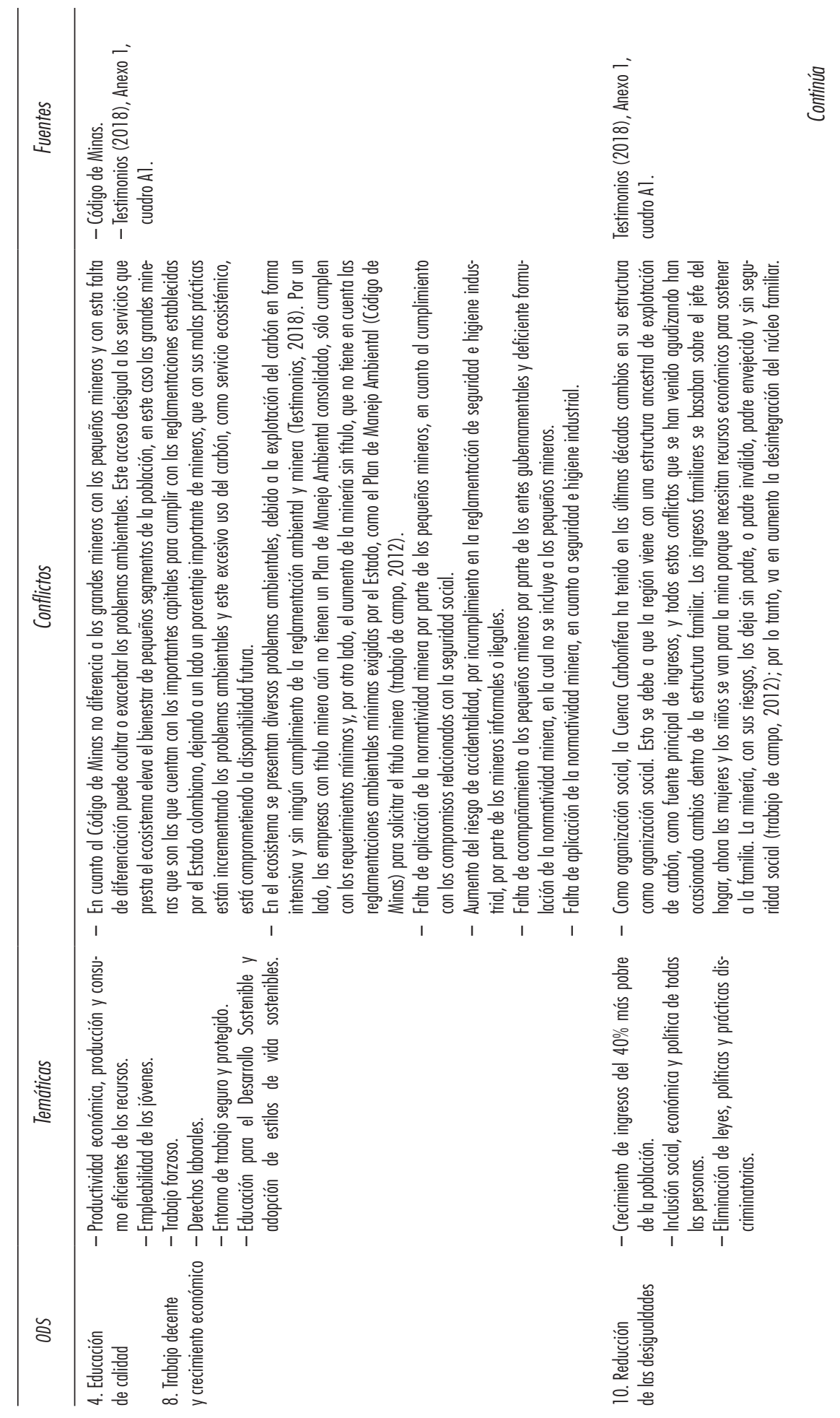




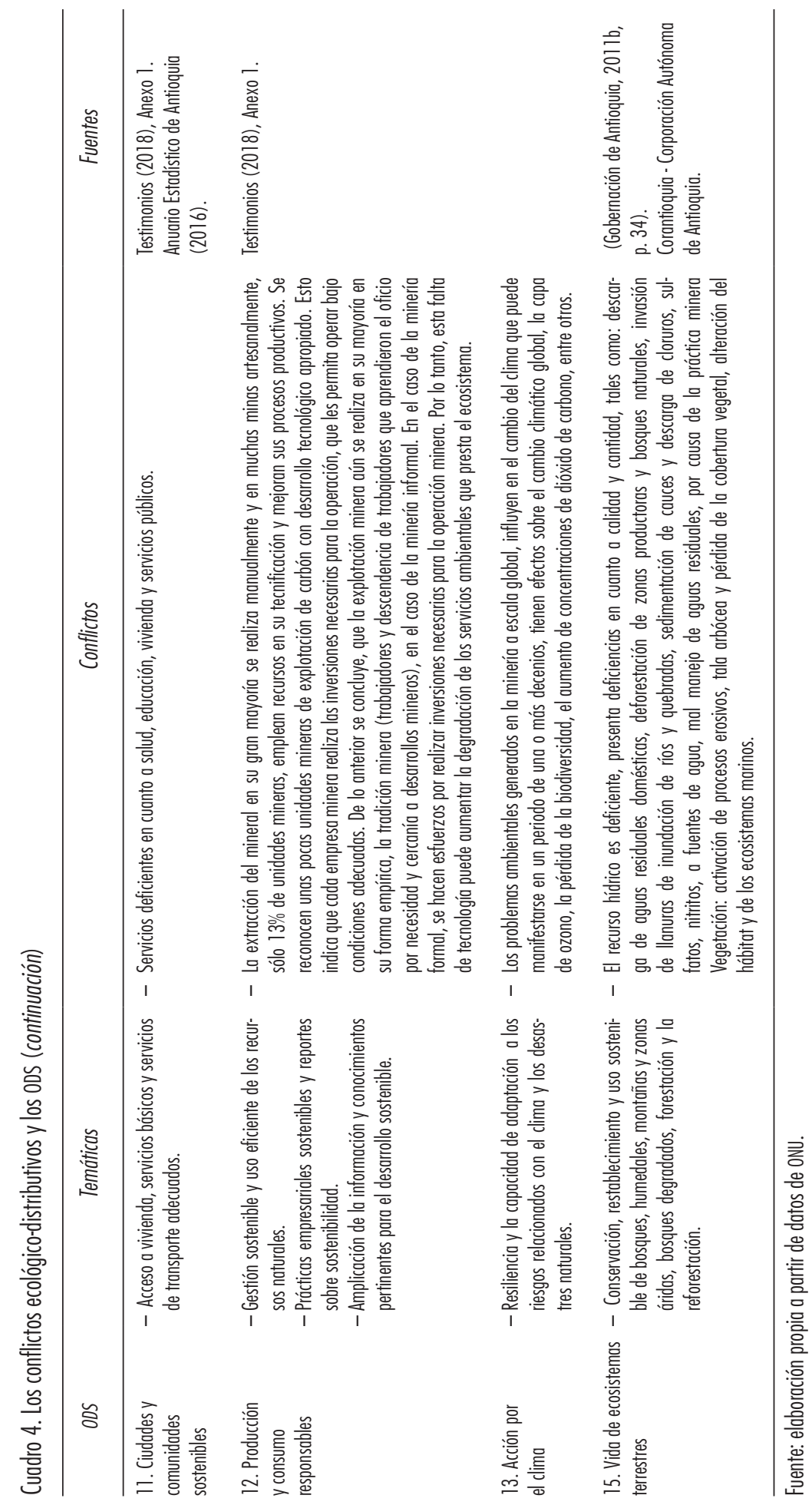




\section{DISCUSIÓN}

\section{La distribución ecológica como objeto de estudio}

La identificación de los cambios o transformaciones (distribución ecológica desigual) que se presentan en el ecosistema se evidencia en el cuadro 5, donde la explotación carbonífera de la Cuenca es un servicio ambiental de fácil acceso para los habitantes y que en la actualidad es la actividad económica principal que genera ingresos para la subsistencia familiar. Pero también la seguridad de la CCS se ve afectada por los cambios que se producen en los otros servicios ambientales de suministro como los alimentos. Asimismo, la actividad minera la realizan bajo riesgo de adquirir enfermedades o lesiones sin tener un seguro de salud adecuado.

En consecuencia, se evidenciaron los servicios ambientales que proporcionan el ecosistema y qué buscan las personas de él, esto permitió destacar la explotación del carbón como la actividad económica principal entre los habitantes de la zona. De la misma manera, revela cómo el bienestar humano tiene múltiples componentes como: los bienes materiales mínimos para una buena vida, la salud, la seguridad, la tecnología, la organización social y las instituciones, y cómo la intervención humana en el ecosistema puede afectar los beneficios de la sociedad, la cual se da a través de impulsores indirectos, que para el caso de la Cuenca se producen por el crecimiento demográfico, el boom minero carbonífero -la sobreexplotación de la minería ilegal o informal-, y la legislación ambiental y minera colombiana.

\section{Los CED como interrogante central}

Desde una mirada integral se identificaron los CED, los cuales desencadenan conflictos de tipo social y económico que van en contra de un Ds en la zona. Esto permite deducir que dentro de los alcances de los CED, existen dos grandes limitantes: la pequeña minería -informal o tradicional-, que se realiza con base en la explotación del carbón sin ningún cumplimiento de requerimiento técnico y ambiental; y la explotación de carbón como actividad económica que tiene una tradición y una costumbre fuerte dentro de los habitantes, y que se considera la principal fuente de sus ingresos.

Desde los distintos intereses o lenguajes de valoración, es difícil que los mineros dejen de trabajar el carbón, ya que su mayor preocupación es la so- 


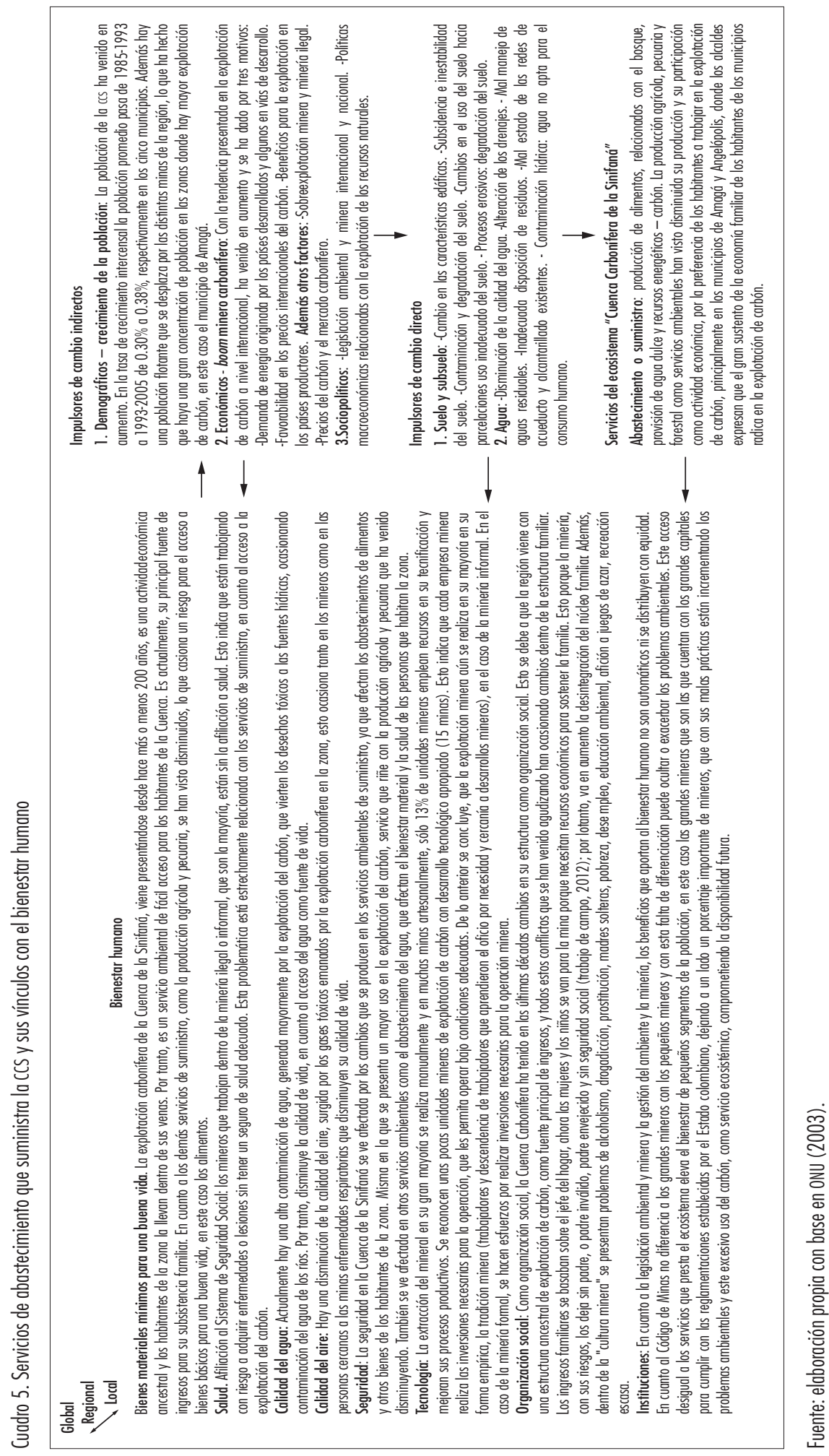


brevivencia y la generación de recursos económicos. Así entonces, los mineros con su interés de un sustento familiar, se torna para él difícil dirimir estos conflictos. Por consiguiente, mientras estas diferencias no se resuelvan continuarán en aumento los conflictos derivados de las malas prácticas mineras y ocasionará una disminución en el bienestar de las generaciones futuras.

\section{CONCLUSIONES}

- Desde los servicios ambientales se están generando transformaciones en el ecosistema, como resultado de las acciones humanas (distribución ecológica desigual). Estos cambios derivados de los CeD presentados en la zona, son en su mayoría ocasionados por la normatividad minera, así como también de la necesidad de los mineros de obtener mejores ingresos económicos.

- El mayor conflicto que se presenta en la zona de estudio se asocia a la insostenibilidad ambiental, derivada de la práctica de la minería ilegal o informal, lo que ha ocasionado un sinnúmero de CED que están impactando en el bienestar de las personas que habitan en la cCs. Además, este conflicto se agudiza cada vez más por el poco control y seguimiento que las autoridades locales y nacionales realizan a las prácticas mineras en la zona.

- La calidad de vida de los habitantes de la zona va en detrimento del bienestar humano, ocasionado por los CED derivados de la explotación del carbón y evidenciado a través del no cumplimiento de los oDs. Esto concluye que en la zona el DS va en disminución, debido a que no están cumpliendo las metas pactadas desde los oDs- Agenda 2030.

- El bienestar humano en la CCS puede aumentar mediante interacciones humanas sostenibles con el ecosistema, es decir, las relaciones respaldadas por eficientes instrumentos de gestión y control de la normatividad minera y ambiental; y reglamentaciones y normativas coherentes con la actividad minera carbonífera y los intereses de la sociedad, teniendo en cuenta los pequeños y medianos mineros de la zona.

- Las interacciones humanas se pueden lograr a través de procesos participativos, ágiles y transparentes entre los usuarios de los servicios del ecosistema, que contribuyan en el fortalecimiento de una mayor seguridad económica, social y ecológica para la zona, es decir, "una seguridad [...], que tenga un nivel mínimo de existencias [...] necesarias para garantizar un flujo sostenible de los servicios que presta el ecosistema” (onU, 2003, 
p. 11), todo esto debe estar encaminado al logro de un Ds que pretende construir una zona con un mejor progreso económico, donde la pobreza extrema esté disminuida o eliminada, donde haya confianza social en las políticas mineras orientadas al bienestar de la comunidad y donde el medio ambiente esté protegido de las malas prácticas mineras.

\section{BIBLIOGRAFÍA}

Adams, W. (1990), "El futuro de la sostenibilidad: repensando el medio ambiente y el desarrollo en el siglo veintiuno". Recuperado de $<$ https://www. oei.es/historico/decada/portadas/iucn_future_of_sustanability_sp.pdf>

Asociación Nacional de Industriales (ANDI) (6 de octubre de 2010), "Revive el debate por la minería ilegal”, Portafolio. Recuperado de $<$ https://www. portafolio.co/economia/finanzas/revive-debate-control-mineria-ilegal285942>

Banco de Iniciativas Regionales para el Desarrollo de Antioquia (BIRD Antioquia) (2011), Potencial minero antioqueño, Medellín-Colombia, L. Vieco e hijas Ltda.

Bebbington, A. (2009), "Actores y ambientalismos: conflictos socio-ambientales en Perú", Revista de Ciencias Sociales. Recuperado de <http://www. redalyc.org/pdf/509/50911906011.pdf>

Berkes F., Colding, J. y Folke, C. (ed.) (2003), Navigating socialecological systems: building resilience for complexity and change, Cambridge, U. K., Cambridge University Press.

Brundtland, G. (1987), Prefacio del presidente. Nuestro Futuro Común. Informe de la Comisión Mundial de Medio Ambiente y el Desarrollo. Recuperado de <http://unesdoc.unesco.org/images/0008/000802/080240so.pdf>

Canut, A. (2007), Desarrollo sustentable y temas afines, Santiago de Chile, Talleres IGD Ltda.

Caracol Radio (17 de junio de 2011), "Un año después de la tragedia, persisten problemas en las minas de Amagá". Recuperado de <http://www. caracol.com.co/noticias/regional/un-ano-despues-de-la-tragedia-persisten-problemas-en-las-minas-de-amaga/20110616/nota/1490292.aspx>

Corantioquia (2006), Plan de Gestión Ambiental Regional 2007-2019. Recuperado de <https:/www.envigado.gov.co/planeacion/SiteAssets/010_ acordeones/documentos/2016/10/Plan\%20de\%20Gesti\%C3\%B3n \%20Ambiental\%20Regional\%20Corantioquia\%202007-2019.pdf> 
(2007), Plan de Ordenación y Manejo Cuenca de la Quebrada Sinifaná. Recuperado de <http://www.corantioquia.gov.co/ciadoc/agua/ga_ cn_7211_2006.pdf>

De Echave, J., Hoetmer, R. y Palacios, M. (2009), Minería y territorio en el Perú. Conflictos, resistencias y propuestas de globalización, Perú, Fondo Editorial de la Facultad de Ciencias Sociales.

Departamento Administrativo de Planeación (2012), Indicadores socioeconómicos de la Cuenca de la Sinifaná [estadísticas], Colombia, Gobernación de Antioquia.

Durand, L., Figueroa, F. y Guzmán, M. (2011), "La ecología política en México. ¿Dónde estamos y para dónde vamos?”, Estudios Sociales. Recuperado de <http://www.scielo.org.mx/scielo.php?script=sci_arttext\&pid= S0-188-45572011000100011>

Escuela Nacional Sindical (16 de julio de 2010), "En Amagá los mineros informales se movilizaron en defensa de su trabajo". Recuperado de $<$ https:// www.colectivodeabogados.org/En-Amaga-los-mineros-informales-se>

Gobernación de Antioquia (2007), "Plan zonal para erradicación del trabajo de los niños, niñas, jóvenes en la Cuenca Carbonífera de la Sinifaná en el Departamento de Antioquia". Recuperado de < https://oitcolombia.org/trabajoinfantil/download/Plan\%20nacional\%20erradicaci\%C3\%B3n\%20del\%20 trabajo\%20infantil_2003.pdfs

González, J.A., Montes, C., Rodríguez, J. y Tapia, W. (2008), "Rethinking the Galapagos Islands as a complex social ecological system: implications for conservation and management", Ecology and Society, vol. 13, núm. 2. Recuperado de <http://www.ecologyandsociety.org/vol13/iss2/art13/>

Henao, A. (2012), "Mineras de Antioquia temen que un decreto las deje sin trabajo", El Tiempo. Recuperado de <http://m.eltiempo.com/economia/ bienestar/mineras-de-antioquia-temen-que-un-decreto-las-deje-sin-trabajo/11385806/1>

Innove (2016), Empresa y Objetivos de Desarrollo Sostenible. Una guia para empezar, Colombia, Taller de Pensamiento y Acción InNove sas.

Lamberti, M. (2010), Una lucha a cielo abierto. El caso del frente amplio opositor a Minera San Xavier (Tesis Maestría), México, Facultad Latinoamericana de Ciencias Sociales.

Martínez-Alier, J. (2001), "Justicia ambiental, sustentabilidad y valoración”. Recuperado de <https://dialnet.unirioja.es/descarga/articulo/153462.pdf> (2004a), "Los conflictos ecológico-distributivos y los indicadores de sustentabilidad”, Revista Iberoamericana de Economía Ecológica, vol. 5, núm. 13. Recuperado de <http://www.redalyc.org/articulo.oa?id=30551307> 
(2004b), El ecologismo de los pobres. Conflictos ambientales y lenguajes de valoración. Recuperado de <https://books.google.com.co/books/about/ El_ecologismo_de_los_pobres.html?id=QRIHSWAACAAJ\&redir_esc=y>

(2009), "Conflictos ecológicos por extracción de recursos y por producción de residuos". Recuperado de <http://revistas.flacsoandes.edu.ec/ letrasverdes/article/view/824>

Martín-López, B., Gómez-Baggethun, E. y Montes, C. (2009), “Un marco conceptual para la gestión de las interacciones naturaleza sociedad en un mundo cambiante". Recuperado de <http://www.ecomilenio.es/wp-content/uploads/2010/10/Martin-et-al-2009-CuIDEs.pdf>

Mata, E. (2009), Incidencia en el Desarrollo Local. Programa de Profesionalización y Fortalecimiento de las Organizaciones Civiles. Recuperado de <http:// www.equipopueblo.org.mx/publicaciones/publicaciones/descargas/INCIDENCIA.pdf>

Montoya, J. (19 de junio de 2010), “El oscuro drama de Amagá”, El Espectador. Recuperado de $<$ http://m.elespectador.com/impreso/nacional/articuloimpreso-209278-el-oscuro-drama-de-amaga>

Najera, P., Solano, V. y López, D. (2011), Impactos Ambientales de la Minería en Colombia, Universidad de la Guajira, Riohacha, Colombia.

Organización de las Naciones Unidas (ONU) (2003), Ecosistemas y Bienestar Humano: Marco para la Evaluación. Informe del Grupo de Trabajo sobre Marco Conceptual de la Evaluación de Ecosistemas del Milenio. Recuperado de <https://www.millenniumassessment.org/documents/document.439.aspx.pdf>

(2018), Agenda 2030 y los Objetivos de Desarrollo Sostenible. Una Oportunidad para América Latina y el Caribe. Recuperado de <https://repositorio.cepal.org/bitstream/handle/11362/40155/24/S1801141_es.pdf>

Ostrom, E. (2009), "A general framework for analyzing sustainability of social-ecological systems", Science, 325. Recuperado de <http://science.sciencemag.org/content/325/5939/419.full>

Palacio, G. (2006), "Breve Guía de Introducción a la Ecología Política (Ecopol)", Gestión y Ambiente. Recuperado de <https://revistas.unal.edu.co/index.php/gestion/article/view/49672>

Pierri, N. (2005), "Historia del Concepto de Desarrollo Sustentable". Recuperadode<https://www.revistavirtualpro.com/biblioteca/historia-delconcepto-de-desarrollo-sustentable>

Portafolio (2012), "En carbón, el país es exportador de talla mundial". Recuperado de <http://www.portafolio.co/negocios/carbon-el-pais-es-exportador-talla-mundial> 
RCN La Radio (15 de marzo de 2012), "En abril comenzarán capacitaciones al sector minero de la Cuenca de Sinifaná. Recuperado de <http://www. rcnradio.com/noticias/editor/en-abril-comenzaran-capacitaciones-al-sector-143425>

Riechmann, J. y Naredo, J. (1995), “De la economía a la ecología: desarrollo sostenible. La lucha por la interpretación". Recuperado de <http://www. istas.ccoo.es/descargas/desost.pdf>

Sachs, J. (2016), La Era del Desarrollo Sostenible, Bogotá, Planeta.

Secretaría de Minas de Antioquia (2012), "Información de la Cuenca de la Sinifaná”. [Apuntes]. Medellín.

Serrano, J. (1997), "Desarrollo sustentable y medio ambiente. Una nueva estrategia global”, Bosque, vol. 18, núm. 2. Recuperado de <http://mingaonline. uach.cl/scielo.php?pid=S0717-92001997000200001\&script=sci_arttext $>$

Sistema de Información Minero Colombiano (simco) (2017), Producción y exportación en Colombia. Recuperado de <https://www.minminas.gov.co/ documents/10192/23966843/270218_produc_expo_carbon_2017. pdf/508970d3-830f-4e8f-8139-36209475fd60>

(2018), Producción y exportación en Colombia. Recuperado de <https:// www.minminas.gov.co/documents/10192/23966843/010617_produc_ expo_carbon_I_2018.pdf/25ffa3dd-1fc6-4d77-ae6f-0614adcc2f75>

Vilardy, S., González, J. A. y Oteros-Rozas, E. (2011), "Los servicios suministrados por los ecosistemas de la ecorregión Ciénaga Grande de Santa Marta", Repensando la Ciénaga: Nuevas miradas y estrategias para la sostenibilidad en la Ciénaga Grande de Santa Marta, Santa Marta-Colombia, Universidad del Magdalena y Universidad Autónoma de Madrid.

y Renán, W. (2011), "Historia y presente de las dinámicas institucionales en la ecorregión Ciénaga Grande de Santa Marta”, Repensando la Ciénaga: Nuevas miradas y estrategias para la sostenibilidad en la Ciénaga Grande de Santa Marta, Santa Marta-Colombia, Universidad del Magdalena y Universidad Autónoma de Madrid.

Walker, B., Holling, C. S., Carpenter, S. R. y Kinzig, A. (2004), "Resilience, adaptability and transformability in social-ecological systems", Ecology and Society 9(2):5. Recuperado de <http://www.ecologyandsociety.org/vol9/ iss $2 / \operatorname{art} 5>$ 


\section{Liliana Lotero Álvarez}

\section{ANEXO}

Cuadro Al. Testimonios de actores relacionados con la cCS

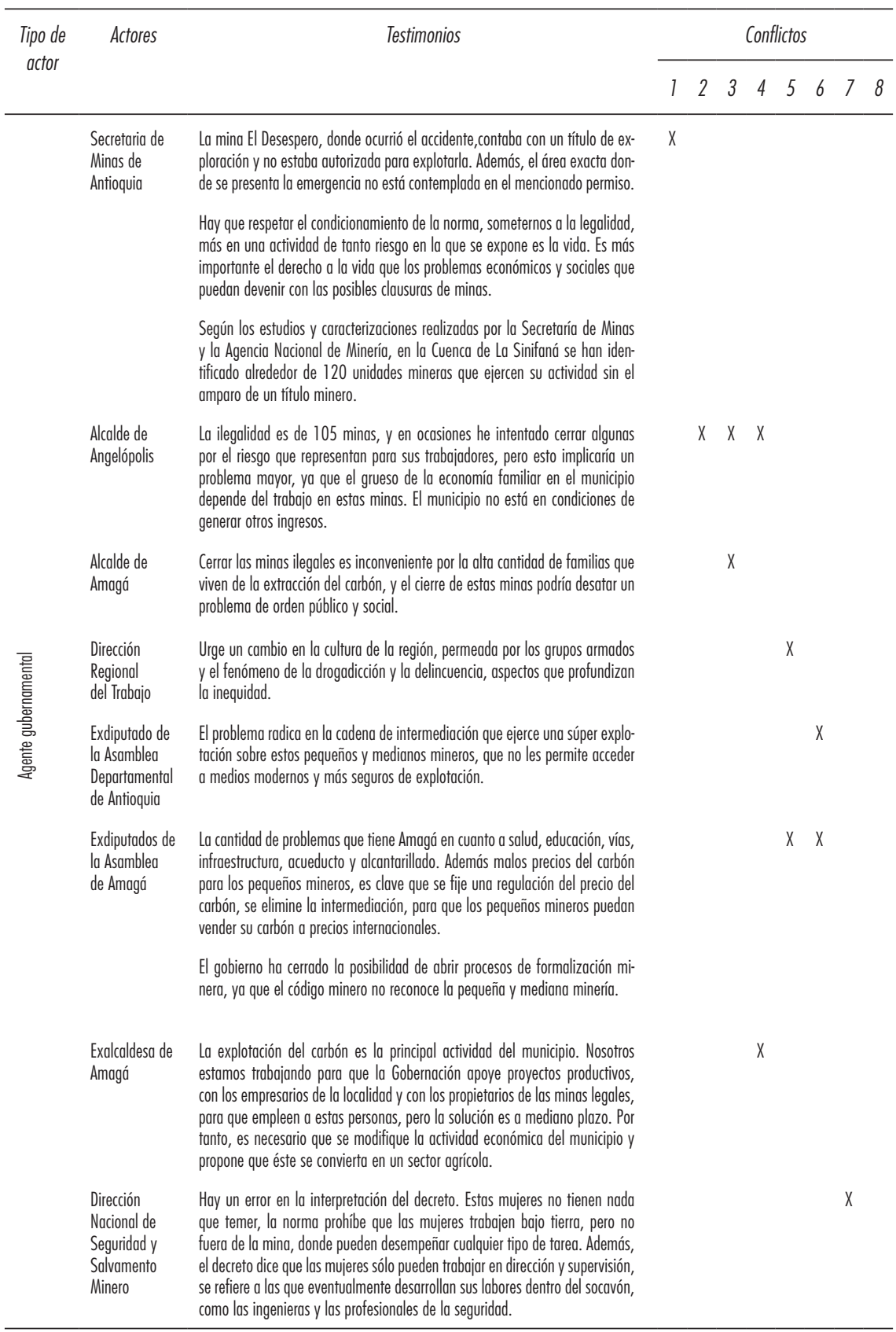




\begin{tabular}{|c|c|c|c|}
\hline \multirow{2}{*}{$\begin{array}{l}\text { Tipo de } \\
\text { actor }\end{array}$} & \multirow[t]{2}{*}{ Actores } & \multirow[t]{2}{*}{ Testimonios } & Conflictos \\
\hline & & & $\begin{array}{llllllll}1 & 2 & 3 & 4 & 5 & 6 & 7 & 8\end{array}$ \\
\hline
\end{tabular}

Propietarios de La gente es muy consciente de que una tragedia puede pasar en cualquier

$X \quad X$ minas mina y es la primera vez que en la zona ocurre un accidente de tal magnitud en una mina tan pequeña.

A pesar de que uno es el que ha trabajado y luchado aquí desde hace años, que uno es el que conoce el terreno, por dónde entrar, dónde trabajar, puede ser sacado en cualquier momento. No nos dejan trabajar.

Trabajadores $\quad Y_{0}$ he trabajado en el socavón, pero me gusta más estar afuera porque los mineros riesgos son menores. Adentro uno no se sabe si va a volver a salir. Me puse a llorar cuando el funcionario del Ministerio de Minas me mencionó ese decreto, porque ¿iyo qué hago?, sino es aquí ¿¿dónde trabaja uno?

Estas tierras están hechas para la minería, aquí la mayoría de personas crecen con el deseo de tener su propia mina y trabajarla.

A los diez años, empecé trabajando en un hueco a la orilla de la carretera, por Angelópolis, en una gurrera, como era tan pequeño cabía por los huecos que los patrones cavaban y de ahí sacaba el carbón.

La alcaldía de Amagá ha luchado por acabar con la minería ilegal a través de seguimientos y capacitaciones con el SENA. El problema es que a los menores de edad es muy difíicl frenarlos y sobre todo cuando la gente se está muriendo de hambre. Las gurreras o minas capoteras son las más peligrosas por el mal mantenimiento que reciben y la falta de garantías que ofrecen a los trabajadores.

La minería nuestra es poco sofisticada, pero la estamos trabajando con buenos montajes, los mineros tienen su linterna, ya no es con velas. Hay menos accidentes que antes. Hemos fallado en cosas, pero ahora estamos tratando de hacer las cosas bien. Es curioso que las grandes empresas legales son las que más muertos han colocado en la zona, en la pequeña minería el número es mucho menor.

Las vías de acceso a los frentes de trabajo son inadecuados y riesgosos, porque cuando pasan cables de alta tensión, todo el personal tocamos esos cables con la espalda porque en algunas partes los socavones tienen apenas metro y medio de alto.

Asociación En materia ambiental el mayor problema está asociado con las prácticas insosNacional de tenibles de la minería ilegal; un cuestionamiento evidente es la imposibilidad Industriales en unos casos y la negligencia en otros, de muchas autoridades ambientales (ANDI) regionales, con respecto a la minería ilegal, lo que hace necesario abrir el debate sobre la estructura, conformación de sus consejos directivos, obligaciones, funciones y sistemas de reporte.

Abogado La ley colombiana eliminó las diferencias en las diferentes modalidades de especialista en minería, sometiéndolas a igualdad de condiciones; se fijó un nuevo esquema minas a través de la figura de la concesión, incluso en áreas de Reserva Minera Especial y se transfirió su autoridad a Municipios y Departamentos. En estos casos, los títulos legales son otorgados a las grandes empresas y los mineros tradicionales con frecuencia son forzados a trabajar en la ilegalidad; en algunos casos, se emprende un proceso legítimo de reasentamiento y compensación para la población y así permitir la minería en gran escala. Sin embargo, en otros, se usa la intervención de los gobiernos 0, incluso, de la fuerza pública para hacer valer los derechos de la empresa privada. Las transformaciones políticas y económicas vividas en los últimos ocho años cambiaron el aspecto del negocio minero en Colombia que, en adelante, recibirá la prioridad para los grandes capitales. 


\section{Liliana Lotero Álvarez}

Cuadro A1. Testimonios de actores relacionados con la ccs (continuación)

\begin{tabular}{|c|c|c|}
\hline $\begin{array}{c}\text { Tipo de } \\
\text { actor }\end{array}$ & Actores & Testimonios \\
\hline 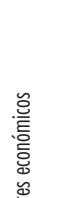 & $\begin{array}{l}\text { Docente } \\
\text { Universidad } \\
\text { de Antioquia- } \\
\text { Sede Medellín }\end{array}$ & $\begin{array}{l}\text { Hoy los mineros que, a pesar de que no son formales y que se les considera } \\
\text { ilegales, vienen avanzando en mejorar el sistema de medición y control de } \\
\text { gases. La técnica de martillo percutor es la que más impacta por el uso de } \\
\text { combustible, pero es la más competitiva. La contaminación se puede mitigar } \\
\text { con filtros a los compresores. } \\
\text { La inseguridad en las minas se debe a la informalidad. }\end{array}$ \\
\hline 要 & $\begin{array}{l}\text { Experto en } \\
\text { seguridad } \\
\text { minera y salud } \\
\text { ocupacional }\end{array}$ & $\begin{array}{l}\text { Aprovecho para hacer un llamado a todas las autoridades mineras para que } \\
\text { no sólo ejerzamos control en Seguridad Industrial en la pequeña y mediana } \\
\text { minería, sino también en las grandes minas de la zona que en los últimos } \\
\text { meses vienen presentando tragedias e incendios de gran magnitud. }\end{array}$ \\
\hline
\end{tabular}

Conflictos

$\begin{array}{llllllll}1 & 2 & 3 & 4 & 5 & 6 & 7 & 8\end{array}$

Asociación de Es una actividad perseguida por el gobierno, que clasifica su actividad como

X

Mineros de la ilegal y le niega la oportunidad de formalizarse. Nosotros no trabajamos al Cuenca de la margen de la ley, nosotros pedimos que se modifique la Ley de Minas para Sinifaná priorizar los derechos de los pequeños mineros, con el fin de acceder a los títulos y respetar su labor, cediendo las hectáreas que requieran para continuar con ella de una manera digna.

La pequeña minería no es el problema sino la solución, ya que genera más de 5 mil empleos directos en toda la región, pero está sola, no tiene ayuda. El Código Minero establece un plazo de dos años para que las minas informales se legalicen y normalicen, sopena de ser cerradas. Las ayudas siempre han sido para los grandes empresarios, pero al pequeño minero nunca se le ha acompañado.

Como prioridad que el gobierno regule el precio del carbón. Pues es la única manera de aumentar los ingresos de los pequeños mineros, que se ven obligados a vender su carbón a bajo precio a comerciantes intermediarios, quienes después lo venden al doble en los mercados de Medellín y otras ciudades del país. Con mejores ingresos los pequeños mineros podrían tecnificar y mejorar la seguridad en sus minas, garantizar las prestaciones y la seguridad social a sus trabajadores y pagar regalías al gobierno.

Lo que dice el gobierno no es real, pues de las 150 solicitudes de legalización de minas del suroeste ninguna ha sido aprobada. Necesitamos que agilicen esos procesos de formalización, pues para los mineros siempre ha sido más rentable abrir un hueco y esperar que lo cierre el Estado. Las autoridades deben diferenciar entre la minería informal y la ilegal: la ilegalidad no es la falta de un título minero o no tener un contrato de operación, es la que está al servicio de grupos al margen de la ley, y si nos cierran las minas nos quitan nuestro medio de subsistir.

Los mineros informales responden a las convocatorias de capacitación que hace el gobierno, y eso tiene alguna utilidad. Pero es insuficiente. Una contribución efectiva sería entregarles permisos de explotación 0 contratos de concesión; darle validez a su antigüedad, pues hay gente con hasta 20 y 30 años en la minería informal. Pero también darles apoyo financiero y brindarles medios técnicos como coches, malacates, ventiladores, energía trifásica, medidores de gas, para que asi puedan mejorar la seguridad en las minas y seguir dando empleo con prestaciones sociales.

El año pasado presentamos propuestas para legalizar minas que cumplen con la normatividad; no hemos tenido respuestas viables, pese a eso seguimos trabajando en cumplir los requerimientos. Esperamos que este año sea posible y nosotros seguiremos empujando esos procesos. También buscamos que haya mejores precios. 


\section{Conflictos socioeconómicos y ambientales derivados de la distribución ecológica}

\begin{tabular}{|c|c|c|}
\hline $\begin{array}{l}\text { Tipo de } \\
\text { actor }\end{array}$ & Actores & Testimonios \\
\hline & $\begin{array}{l}\text { Asociación de } \\
\text { Mineros de la } \\
\text { Cuenca de la } \\
\text { Sinifaná }\end{array}$ & $\begin{array}{l}\text { Desde hace años, el Estado ha adelantado un plan de regularización que ha } \\
\text { terminado entregándoles tierra, minas y concesiones a multimillonarios ajenos } \\
\text { a la región. El iletrado sigue siendo el ilegal de este país. Las grandes empre- } \\
\text { sas se abstienen de comprarles a ellos, pero lo hacen a los intermediarios, que } \\
\text { se quedan con la mayor parte del botín. "¿Quién es más ilegal, el pequeño } \\
\text { minero o el gran empresario que les compra a los intermediarios ilegales que } \\
\text { nos compran a nosotros? Somos los que estamos enriqueciéndolos a ellos". }\end{array}$ \\
\hline & $\begin{array}{l}\text { Sociólogo de } \\
\text { la Universidad } \\
\text { Pontificia } \\
\text { Bolivariana }\end{array}$ & $\begin{array}{l}\text { De acabar con las prácticas tradicionales de la minería, no sólo se excluiría del } \\
\text { mercado a la pequeña empresa, sino que el nivel de desempleo en la zona } \\
\text { se incrementaría, pues la gran industria no es capaz de integrar a los } 6 \text { mil } \\
\text { mineros artesanales que ahora se dedican a esas actividades. Mientras las } \\
\text { autoridades no ejerzan controles o promuevan una asignación presupuestal } \\
\text { focalizado en la sostenibilidad de la pequeña minería, incentivando a la forma- } \\
\text { lización y, por ende, la disminución de los riesgos laborales y ambientales, los } \\
\text { pequeños productores están obligados a permanecer en la ilegalidad. }\end{array}$ \\
\hline
\end{tabular}

300 mineros - $\quad$ Nos podemos caer, nos podemos herir, nos podemos morir y aún así necesimarcha minera tamos nuestro trabajo.

de Amagá 2010

Personas del Es imposible, toda la vida gira en torno a la minería. No nos queda más desticomún no que ir al huequito (la mina), en la agricultura no hay nada que hacer, para llevar la comida a la casa. Como dicen en el mismo municipio, unos mueren para que otros vivan y ganen.

Digan lo que digan, toca seguir trabajando en esto porque por aquí no hay más empleo.

Desafortunadamente en el municipio aún no hay conciencia sobre el tema de la seguridad minera, por lo que se viene trabajando con los mineros para que se organicen, legalicen y cumplan la normatividad sobre seguridad minera.

En Colombia a diario mueren tres personas por accidentes de trabajo, y es la minería la que pone la mayor parte, razón por la cual la olt ha exigido políticas especiales para este sector. El modelo de seguridad industrial en Colombia tiene muchas fallas. La primera es que las ARP, encargadas de dar asesoría técnica a las empresas mineras, no la están dando porque desconocen esta actividad. El Estado, que debe vigilarla a través de los ministerios de minas y protección social, no lo está haciendo adecuadamente. Y las empresas no tienen programas eficaces y coherentes con el riesgo de la actividad.

Las condiciones de seguridad en las minas de carbón en el municipio de Amagá son muy diversas, y persisten los grandes riesgos para la explotación de esos minerales, especialmente por el gran número de socavones y minas que aún trabajan en la informalidad.

La minería de tradición ha sido abandonada por el Estado, y no ha habido ayuda para salir adelante. En cambio, las empresas grandes, que ni son mineros, piden un título y se los dan.

En el último año se ha incrementado el acompañamiento de entidades del Estado, como la Secretaría de Minas, Ingeominas, y el Ministerio de la Protección Social, pero aún falta mayor inversión y acompañamiento a los pequeños mineros, que es donde se presentan las grandes dificultades.

$\begin{array}{llllllll}1 & 2 & 3 & 4 & 5 & 6 & 7 & 8\end{array}$

Exdirectivo Ingeominas debería adelantar programas de prevención de desastres, levantar sindical planos de evacuación de las minas, prestar asistencia técnica en forma regular, y no limitarse sólo al lamentable papel de sacar muertos. 


\section{Liliana Lotero Álvarez}

Cuadro A1. Testimonios de actores relacionados con la ccs (continuación)

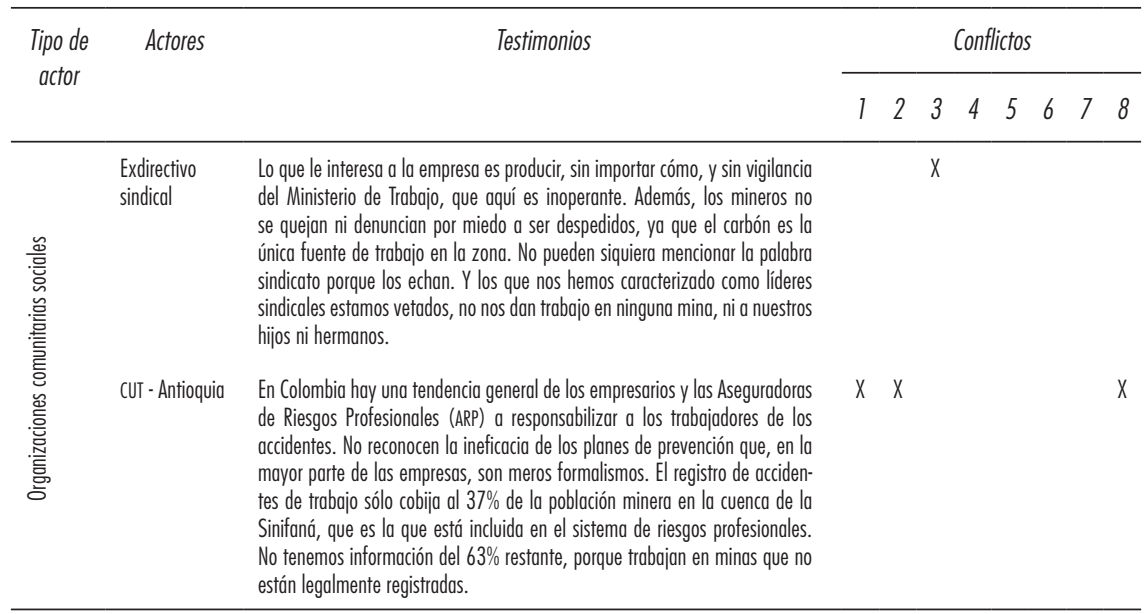

Número de respuestas:

$\begin{array}{llllllll}10 & 13 & 8 & 3 & 2 & 4 & 3 & 11\end{array}$

Fuente: Escuela Nacional Sindical (16 de julio de 2010); RCN La Radio (15 de marzo de 2012); Henao, A. (2012); Montoya, J. (19 de junio de 2010); Secretaría de Minas de Antioquia (2012); Caracol Radio (17 de junio de 2011).

Cuadro A2. Testimonios de actores relacionados con la ces (descripción de conflictos)

\begin{tabular}{|c|c|c|}
\hline $\begin{array}{l}\text { Número de } \\
\text { conflicto }\end{array}$ & Conflictos & $\begin{array}{l}\text { Número de } \\
\text { respuestas }\end{array}$ \\
\hline 1 & $\begin{array}{l}\text { Falta de aplicación de la normatividad minera y ambiental, en cuanto a incumplimiento en los } \\
\text { compromisos relacionados con la seguridad social. }\end{array}$ & 10 \\
\hline 2 & $\begin{array}{l}\text { Falta de aplicación de la normatividad minera y ambiental, en cuanto a seguridad e higiene } \\
\text { industrial. }\end{array}$ & 13 \\
\hline 3 & Necesidad de generación de ingresos para la subsistencia familiar. & 8 \\
\hline 4 & Disminución de la producción pecuaria y agrícola. & 3 \\
\hline 5 & Servicios deficientes en cuanto a salud, educación, vivienda y servicios públicos. & 2 \\
\hline 6 & Cadena de intermediación/ comercialización del carbón. & 4 \\
\hline 7 & $\begin{array}{l}\text { Deficiente formulación de la normatividad minera, en la cual no se incluye a los grupos } \\
\text { vulnerables (mujeres, niños, adultos mayores). }\end{array}$ & 3 \\
\hline 8 & Falta de acompañamiento a los pequeños mineros por parte de los entes gubernamentales. & 11 \\
\hline
\end{tabular}

Fuente: elaboración propia. 